\title{
Dramatically Amplified Thoracic Sympathetic Postganglionic Excitability and Integrative Capacity Revealed with Whole-Cell Patch-Clamp Recordings
}

\author{
DiD Michael Lee McKinnon, ${ }^{1}$ Kun Tian, ${ }^{2}$ Yaqing Li, ${ }^{1}$ Alan Joel Sokoloff, ${ }^{1}$ Meredith Lucy Galvin, ${ }^{1}$ (D) Mi Hun \\ Choi, ${ }^{1}$ - Astrid Prinz, ${ }^{2}$ and ${ }^{-S}$ Shawn Hochman ${ }^{1}$
}

https://doi.org/10.1523/ENEURO.0433-18.2019

${ }^{1}$ Department of Physiology, Emory University, Atlanta, GA 30322 and ${ }^{2}$ Department of Biology, Emory University, Atlanta, GA 30322

\begin{abstract}
Thoracic paravertebral sympathetic postganglionic neurons (tSPNs) comprise the final integrative output of the distributed sympathetic nervous system controlling vascular and thermoregulatory systems. Considered a non-integrating relay, what little is known of tSPN intrinsic excitability has been determined by sharp microelectrodes with presumed impalement injury. We thus undertook the first electrophysiological characterization of tSPN cellular properties using whole-cell recordings and coupled results with a conductance-based model to explore the principles governing their excitability in adult mice of both sexes. Recorded membrane resistance and time constant values were an order of magnitude greater than values previously obtained, leading to a demonstrable capacity for synaptic integration in driving recruitment. Variation in membrane resistivity was the primary determinant controlling cell excitability with vastly lower currents required for tSPN recruitment. Unlike previous microelectrode recordings in mouse which observed inability to sustain firing, all tSPNs were capable of repetitive firing. Computational modeling demonstrated that observed differences are explained by introduction of a microelectrode impalement injury conductance. Overall, tSPNs largely linearly encoded injected current magnitudes over a broad frequency range. Thus, whole-cell recordings reveal tSPNs have more dramatically amplified excitability than previously thought, with greater intrinsic capacity for synaptic integration and with the ability for maintained firing to support sustained actions on vasomotor tone and thermoregulatory function. Rather than acting as a relay, these studies support a more responsive role and possible intrinsic capacity for tSPNs to drive sympathetic autonomic function.
\end{abstract}

Key words: computational model; firing properties; membrane properties; mouse; paravertebral ganglia

\section{Significance Statement}

Thoracic sympathetic postganglionic neurons (tSPNs) represent the final neural output for control of vasomotor and thermoregulatory function. We used whole-cell recordings and computational modeling to provide broad insight on intrinsic cellular mechanisms controlling excitability and capacity for synaptic integration. Compared to past intracellular recordings using microelectrode impalement, we observed dramatically higher membrane resistivity with primacy in controlling enhanced tSPN excitability and recruitment via synaptic integration. Compared to reported phasic firing, all tSPNs fire repetitively and linearly encode injected current magnitude to firing frequency over a broad range. Modeling studies suggest microelectrode impalement injury accounts for differences in tSPN properties previously observed. Overall, intrinsic tSPN excitability plays a much greater role in the integration and maintenance of sympathetic output than previously thought. 


\section{Introduction}

Sympathetic postganglionic neurons (SPNs) within paravertebral chain ganglia represent a large fraction of the final output of the sympathetic nervous system. Whereas prevertebral sympathetic ganglia are typically associated with one or more visceral organs in a discrete location (celiac ganglion, superior/inferior mesenteric ganglion), thoracic paravertebral chain ganglia are associated with control of dispersed tissue systems such as vasculature, brown adipose tissue, sweat glands, and piloerector muscles (Jänig, 2006; Bartness et al., 2010). As such, the sympathetic chain can be thought of as a distribution system for sympathetic activity that spans the body. The vast majority of paravertebral postganglionic neurons in mice are adrenergic (Gibbins, 1991; Jobling and Gibbins, 1999) since sweat glands, innervated by cholinergic postganglionic neurons, are largely absent in the mouse (Lu and Fuchs, 2014).

Traditionally, thoracic SPNs (tSPNs) have been envisioned as passive followers of intraspinal preganglionic neuronal activity. By this viewpoint, postganglionic neurons fire if and only if preganglionics fire and serve as 1:1 relays that pass central commands to the periphery (Jänig, 2006). This relationship is explained by the " $n+1$ " rule, wherein postganglionic neurons receive $\mathrm{n}$ small synaptic inputs, and one major, always suprathreshold input which leads to firing with a high safety factor. The $\mathrm{n}$ smaller synaptic inputs are typically sub-threshold and infrequent, and are not thought to contribute appreciably to the firing rate (McLachlan et al., 1998; Karila and Horn, 2000; McLachlan, 2003; Wheeler et al., 2004; Rimmer and Horn, 2010). However, recent evidence from rodent sympathetic ganglia has shown that postganglionic neurons play a more active role in shaping sympathetic output (Bratton et al., 2010; Springer et al., 2015). In light of these findings, we must reconsider the role that SPNs play in synaptic integration and signal transmission.

Despite their critical importance as the final output controlling sympathetic neural commands, surprisingly little is known about the SPNs in thoracic segments (tSPNs) of the sympathetic chain. The most likely reason for this is their near inaccessibility to in vivo study, and the relative difficulty for in vitro cellular characterization. Be-

Received November 6, 2018; accepted April 16, 2019; First published April 30, 2019.

The authors declare no competing financial interests.

Author contributions: M.L.M., K.T., A.P., and S.H. designed research; M.L.M., K.T., Y.L., A.J.S., M.L.G., M.H.C., and S.H. performed research; M.L.M., K.T., A.J.S., M.L.G., and M.H.C. analyzed data; M.L.M., K.T., A.P., and S.H. wrote the paper.

This work was supported by the National Institutes of Health Grant 5R01NS102871 and the Department of Defense Grant SCI-30225. M.L.M. was supported by a fellowship from the National Science Foundation (GRFP), and K.T. was supported by a fellowship from the Emory Center for Mind, Brain, and Culture (CMBC).

Correspondence should be addressed to Shawn Hochman at shochm2@emory.edu

https://doi.org/10.1523/ENEURO.0433-18.2019

Copyright (C) 2019 McKinnon et al.

This is an open-access article distributed under the terms of the Creative Commons Attribution 4.0 International license, which permits unrestricted use, distribution and reproduction in any medium provided that the original work is properly attributed. cause of this difficulty, electrophysiological properties of sympathetic neurons have been largely inferred from recordings in other mammalian paravertebral sympathetic ganglia, namely the superior cervical ganglion (SCG; Eccles, 1935; Erulkar and Woodward, 1968; Purves and Wigston, 1983; Li and Horn, 2006) and to a lesser extent the stellate and lumbar ganglia (Jänig, 1985; Cassell et al., 1986; Valli et al., 1989; Bratton et al., 2010). Compared to SCG, mouse tSPNs are smaller, have less elaborate dendritic arbors, are likely more excitable, and differ in measures of action potential (AP) shape (Jobling and Gibbins, 1999). Thoracic ganglia also contain a different subset of molecularly distinct SPN subpopulations and project to different end-organs (Jänig, 2006; Furlan et al., 2016). Unfortunately, few studies have directly characterized electrophysiological properties of thoracic ganglia (Blackman and Purves, 1969; Lichtman et al., 1980; Jobling and Gibbins, 1999). These studies used sharp microelectrodes for recordings, which likely introduce a considerable impalement injury conductance compared to wholecell patch-clamp recordings (Staley et al., 1992; Springer et al., 2015). This injury-induced conductance alters basic membrane properties, such as input resistance and membrane time constant, which reduce recruitment and synaptic integrative actions according to classical cable theory (Rall, 2011; Springer et al., 2015). The impalement conductance introduced by microelectrode recordings can also prevent expression of repetitive firing properties (Cymbalyuk et al., 2002; Springer et al., 2015). Indeed, while it is generally thought that most paravertebral SPNs fire phasically (Cassell et al., 1986; Jobling and Gibbins, 1999; Li and Horn, 2006), whole-cell recordings in SCG support repetitive rather than phasic firing (Springer et al., 2015). Whether repetitive firing properties are predominant in tSPNs remains unknown.

The aim of the present study is to investigate the electrophysiological properties of tSPNs using whole cell recordings to more accurately characterize the cellular mechanisms that drive and modulate excitability of tSPNs. We furthermore matched recordings to a computational model to better understand how synaptic inputs and passive and active membrane properties interact to recruit neurons and generate the firing properties observed.

\section{Materials and Methods}

\section{Animals}

All animal procedures were performed in accordance with the Emory University Institutional Animal Care and Use Committee's regulations and conformed to the Guide for the Care and Use of Laboratory Animals. Experiments were performed on adult (P37-P379) C57BL/6 mice (RRID:IMSR_JAX:000664). Mice were anesthetized with inhaled isoflurane and maintained or killed with urethane (intraperitoneal injection, $40 \mathrm{mg} / \mathrm{kg}$ for transcardial perfusions, $\sim 500 \mathrm{mg} / \mathrm{kg}$ for in vitro electrophysiology). Complete sedation or death was confirmed by lack of foot pinch and eye blink reflex. 


\section{Immunohistochemistry}

Neurotransmitter identity

Two ChAT-eGFP mice (RRID:IMSR_JAX:007902), a male and a female (P91 and P101, respectively) were anesthetized and transcardially perfused with heparinized saline $\left(0.9 \% \mathrm{NaCl}, 0.1 \% \mathrm{NaNO}_{2}, 10\right.$-units $/ \mathrm{ml}$ heparin), followed by $4 \%$ paraformaldehyde $(0.5 \mathrm{M}$ phosphate, $4 \%$ paraformaldehyde, $\mathrm{NaOH}$ ). Tissue was post-fixed overnight, then transferred to a $15 \%$ sucrose solution and stored at $4^{\circ} \mathrm{C}$. Sympathetic chains were isolated from stellate ( $T 1$ and $T 2$ ) to $T 12 / 13$. Tissue was embedded (TissueTek optimal cutting temperature compound), sectioned on a cryostat $\left(-21^{\circ} \mathrm{C}, 8-\mu \mathrm{m}\right.$ slice thickness), and mounted on glass slides. Tissue was washed in $0.1 \mathrm{M}$ PBS for $1 \mathrm{~h}$ and permeabilized with PBS containing $0.3 \%$ Triton X-100 (PBS-T) overnight. Sections were subsequently incubated for 2-3 d with primary antibodies: sheep anti-tyrosine hydroxylase (TH; Millipore, 1:100, RRID:AB_90755) and chicken anti-green fluorescent protein (Jackson, 1:100). Preparations were then washed in PBS-T $(3 \times 30 \mathrm{~min})$ and incubated for $1.5 \mathrm{~h}$ with secondary antibodies: Cy3 donkey anti-sheep (Abcam, 1:250) and Alexa Fluor 488 donkey anti-chicken (Abcam, 1:250). Slides were washed a final time in PBS-T (20 min), then 50 $\mathrm{mM}$ Tris- $\mathrm{HCl}(2 \times 20 \mathrm{~min})$ and allowed to dry before being coverslipped [SlowFade Gold antifade reagent with 4',6diamidino-2-phenylindole (DAPI)]. Sections were visualized under a fluorescent microscope (Olympus BX51). Cells with visible nuclei were counted and assessed for neurotransmitter identity. Interanimal cell count variability was substantial (6494 vs 19,721 cells).

\section{Cell diameter}

Six C57BI/6J mice (RRID:IMSR_JAX:000664), 5 males and one female (all $\sim$ P60) were transcardially perfused, as above. T5 Sympathetic ganglia were isolated. Unmounted tissue was washed in PBS-T overnight. Slides were subsequently incubated for $5 \mathrm{~d}$ with sheep anti-TH (Millipore, 1:100, RRID:AB_90755). Preparations were then washed in PBS-T $(3 \times 2 \mathrm{~h})$ and incubated for $3 \mathrm{~d}$ with Alexa Fluor 488 donkey anti-sheep (Jackson, 1:100). Slides were washed a final time in PBS-T ( $2 \mathrm{~h})$, then $50 \mathrm{mM}$ Tris- $\mathrm{HCl}(2 \times$ $1 \mathrm{~h})$. Intact ganglia were mounted on glass slides and coverslipped (SlowFade Gold antifade reagent with DAPI). THimmunoreactive cells were visualized under a fluorescent microscope (Olympus BX51, 40× objective) using a Microfire digital camera (Optronics), and traced using Neurolucida software (MBF Bioscience, RRID:SCR_001775). Cell diameters were calculated as the arithmetic mean of minimum and maximum Feret. Diameter was only determined for cells with a discernible perimeter (176 \pm 131 cells per ganglion) representing a mean $71 \%$ of the total $\mathrm{TH}^{+}$cell population (range of 36-95\% neurons/ganglia measured). As diameter distributions were comparable between ganglia, the possibility of sampling bias in estimated cell diameter is unlikely. Results are reported as mean \pm SD.

\section{Electrophysiology}

\section{Tissue preparation}

Mice were killed and the spinal column was quickly dissected out with sympathetic chain and spinal roots attached. Figure $1 A$ provides a simplified schematic of the anatomic organization of intraspinal preganglionic and paravertebral postganglionic neurons. The remaining tissue was incubated in continually oxygenated ACSF containing collagenase (20-mg Type III per 1-ml ACSF, Worthington Biochemical Corporation) for $1.5 \mathrm{~h}$. ACSF used for incubation was buffered with either bicarbonate or HEPES. No difference was observed as a result of incubation buffer. Following incubation, tissue was vortexed to remove adherent fat and washed with ACSF several times to eliminate residual collagenase. The intact sympathetic chain was removed by severing rami, and was then pinned down into a clear Sylgaard recording dish (Fig. 1B), through which recirculating, oxygenated ACSF was continually perfused.

Whole-cell recordings Whole-cell patch recordings were obtained from postganglionic cells at room temperature. Cells were identified using an upright microscope (Olympus, BX51WI) affixed with a low-light camera (Olympus, OLY-150). Patch electrodes were pulled on a vertical puller (Narishige, PP-83) from 1.5-mm outer diameter filamented, borosilicate glass capillaries (World Precision Instruments, stock \#TW150F-4) for a target resistance of 5-9 MOhm. Signals were amplified using a MultiClamp 700A and digitized at $10 \mathrm{kHz}$ using a Digidata $1322 \mathrm{~A}$ and Clampex software (Molecular Devices, RRID:SCR_011323).

We considered for analysis all cells which displayed clearly defined APs on depolarization by square current steps. Of these, cells were excluded if more than $100 \mathrm{pA}$ was required to hyperpolarize a cell to $-70 \mathrm{mV}$ (indicative of a significant leak), if APs appeared stunted (indicative of an incomplete breakthrough), or if membrane potential was highly variable (indicative of improper seal formation). All cells which met these criteria $(n=35)$ had resting membrane potentials more negative than $-50 \mathrm{mV}$ and input resistances higher than $200 \mathrm{M} \Omega$. All recordings were made in ACSF containing: $127.99 \mathrm{mM} \mathrm{NaCl}, 1.90 \mathrm{mM}$ $\mathrm{KCl}, 1.30 \mathrm{mM} \mathrm{MgSO}{ }_{4} \cdot 7 \mathrm{H}_{2} \mathrm{O}, 2.40 \mathrm{mM} \mathrm{CaCl}_{2} \cdot 2 \mathrm{H}_{2} \mathrm{O}, 1.20$ $\mathrm{mM} \mathrm{KH_{2 }} \mathrm{PO}_{4}, 9.99 \mathrm{mM}$ glucose, and $26.04 \mathrm{mM} \mathrm{NaHCO}_{3}$. ACSF pH was adjusted to 7.4 after saturation with gas $\left(95 \% \mathrm{O}_{2}, 5 \% \mathrm{CO}_{2}\right)$ at room temperature. Intracellular patch-clamp solution contained: $140.0 \mathrm{mM} \mathrm{K-gluconate,}$ $11.0 \mathrm{mM}$ EGTA, $10 \mathrm{mM}$ HEPES, and $1.32 \mathrm{mM} \mathrm{CaCl}_{2} ; \mathrm{pH}$ was adjusted to 7.3 using $\mathrm{KOH}$. Target osmolarity was $<290$ mOsm. In most recordings (25/39 cells), support solution was added consisting of $4.0 \mathrm{mM}$ ATP and $1.0 \mathrm{mM}$ GTP.

The ratio of male to female mice was $\sim 1: 1$. Recordings were taken from the right thoracic ganglia, with the majority of recordings coming from T5. The number of cells from ganglia T3 through T12 was 2, 6, 17, 3, 2, 1, 1, 0, 1, and 2 , respectively. We initially assessed sex and segment related differences in cell properties. Our sample size precludes a more detailed analysis of segmentspecific differences, but we were able to pool data from rostral (T3 and T4) and caudal (T5 to T12) segments (Furlan et al., 2016). Statistical tests revealed no differences with respect to sex or rostro-caudal location ( $t$ test, two-tailed, unequal variance, Šidák corrected $\alpha=$ 0.0019), so all data were pooled for additional analyses. 
A

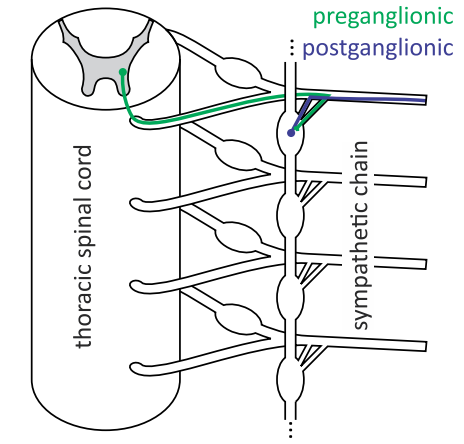

B
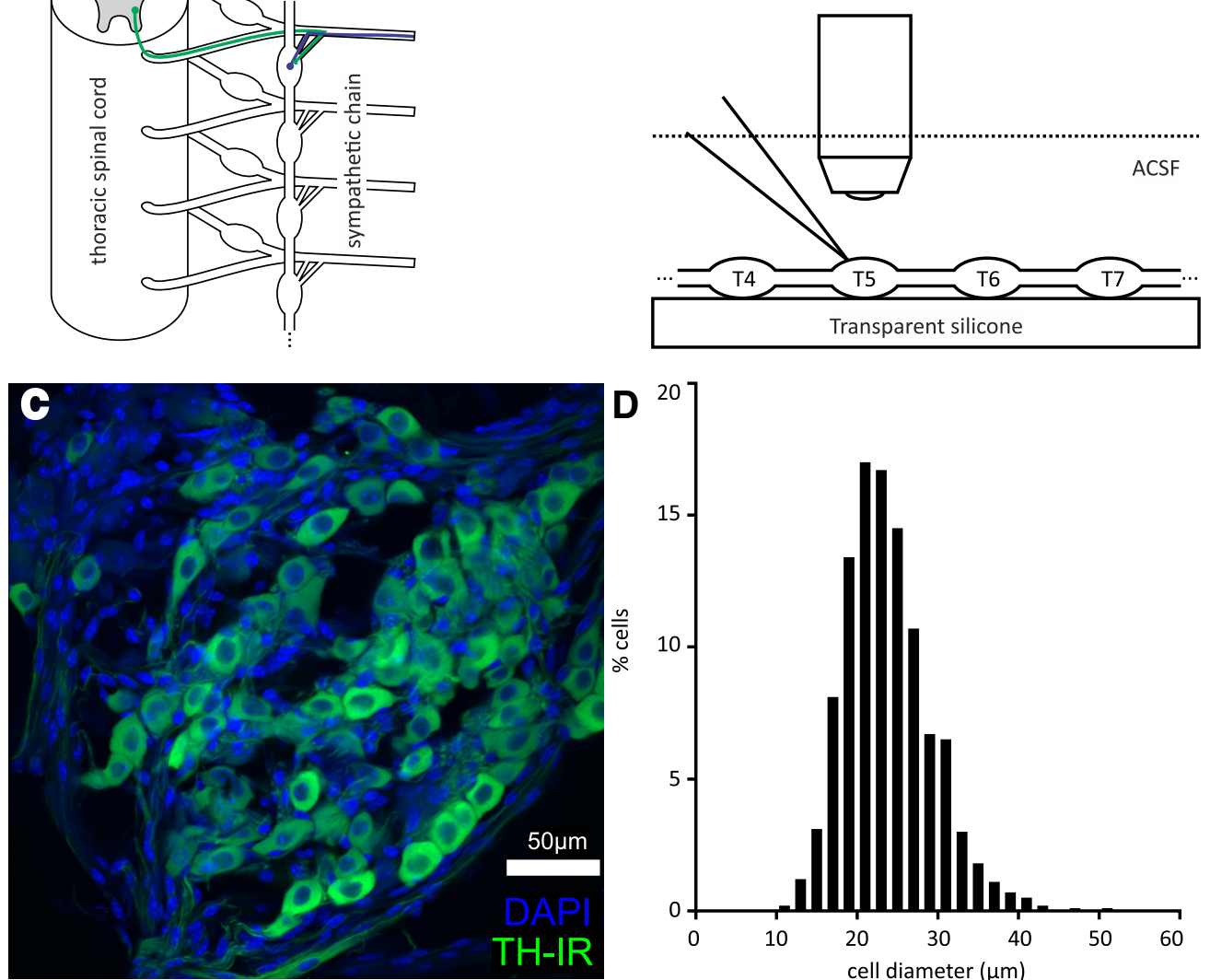

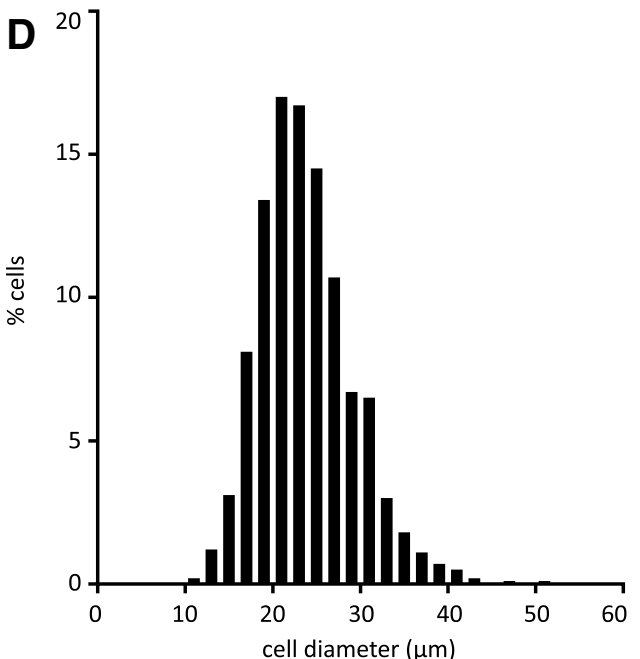

Figure 1. Cell size and composition. $\boldsymbol{A}$, Simplified schematic depicting the anatomic organization of preganglionic and postganglionic neurons. $\boldsymbol{B}$, Recording setup. Sympathetic chains are pinned down in a silicone chamber, superfused with oxygenated ACSF. They are then visualized under a microscope and recorded using a glass patch-clamp electrode. $\boldsymbol{C}$, Confocal slice through whole-mounted tissue showing TH immunolabeling and nuclear labeling with DAPI. Note the numerous smaller and more intensely labeled nuclei that are presumably non-neuronal cells. Scale bar represents $50 \mu \mathrm{m}$. $\boldsymbol{D}$, Histogram showing distribution of TH-IR cell diameters in T5 ganglia of six animals.

\section{Data analysis}

All cellular properties were analyzed in Clampfit (Molecular Devices, RRID:SCR_011323) or MATLAB (MathWorks, RRID:SCR_001622). All parameters were estimated from a single set of current steps for each cell. This ensured that parameters for a given cell were estimated at nearly the same point in time. In current clamp mode, membrane voltage response to hyperpolarizing current steps of at least $1.5 \mathrm{~s}$ was fit to an exponential of the form Equation 1 using the Levenberg-Marquardt algorithm built in to Clampfit. The value of membrane time constant $\left(\tau_{\mathrm{m}}\right)$ was calculated in this manner (Golowasch et al., 2009). $R_{\text {in }}$ was estimated by dividing maximal voltage deflection $(\Delta V)$ by the injected current $\left(I_{\text {inj; }}\right.$, Eq. 2$)$. Membrane capacitance $\left(\mathrm{C}_{\mathrm{m}}\right)$, a measure of total cell surface area, was estimated by dividing $\tau_{\mathrm{m}}$ by $\mathrm{R}_{\text {in }}$ (Eq. 3 ).

$$
\begin{gathered}
\Delta V \cdot \exp \left(-t / \tau_{m}\right)+\left(V_{\text {hold }}-\Delta V\right) \\
R_{\text {in }}=\Delta V / I_{\text {inj }} \\
C_{m}=\tau_{m} / R_{\text {in }}
\end{gathered}
$$

Measured rheobase current $\left(I_{\text {rheo }}\right)$ was taken as the smallest long-duration (1.5 s or longer) positive current injection which elicited a single spike. In the case that an incremental increase in current elicited multiple spikes, rheobase was estimated to be the mean of the adjacent subthreshold and suprathreshold steps, e.g., if $30 \mathrm{pA}$ did not elicit any spikes but $40 \mathrm{pA}$ elicited several, the measured rheobase estimate would be $35 \mathrm{pA}$. to achieve a more finely-grained estimate of rheobase, we also calculated rheobase based on the equation:

$$
\hat{l}_{\text {rheo }}=\left(V_{\text {th }}-V_{\text {hold }}\right) / R_{\text {in }}
$$

where $V_{\text {th }}$ is the AP threshold, taken to be the point at which the first derivative of voltage, $d V_{m} / d t$, begins to increase (Platkiewicz and Brette, 2010). Measured values related to AP and post-spike afterhyperpolarization (AHP) characteristics were taken from traces elicited at minimal suprathreshold current, i.e. the smallest current magnitude used which elicited at least one AP.

The parameters of the fast AHP (fAHP) varied as a function of firing rate, so analysis of fAHP properties was 
limited to cells which fired a single spike at minimal suprathreshold current intensity. AP amplitude was defined as the difference between the peak voltage and threshold. AP halfwidth is the width of the spike at half AP amplitude. fAHP amplitude was defined as the difference between peak negative voltage and steady-state voltage at rheobase current injection. fAHP half-decay is the time it takes for the fAHP to decay to half its amplitude. fAHP duration is the time between spike onset and return to baseline (Hochman and McCrea, 1994). Slow AHP (sAHP) amplitude was defined as the difference between peak negative voltage and baseline (holding voltage). SAHP half-decay is the time it takes for the SAHP to decay to half its amplitude.

Instantaneous firing rate (IFR) was taken as the inverse of the interspike interval. Maximal firing rate was the IFR for the first spike pair at the beginning of current onset. Sustained firing rate was the mean IFR for the last three interspike intervals, given they occur during the last half of the depolarizing current step. Frequency-current $(f-l)$ slope is the slope of the linear regression of the $f$-I curve. The spike rate adaptation (SRA) ratio is defined as the ratio between the maximal and sustained firing rate at a given current injection (Venance and Glowinski, 2003; Miles et al., 2005). To directly compare firing rate across cells with variable $R_{\text {in }}$ and $f$-I curves, we used the sustained firing rate at twice minimal suprathreshold current injection. Current step duration was at least $1.5 \mathrm{~s}$ for all cells, and $3 \mathrm{~s}$ for the majority. Liquid junction potential was calculated to be $-9.8 \mathrm{mV}$ and empirically measured to be $-13 \mathrm{mV}$. All values of absolute voltage (resting membrane potential, absolute threshold, peak voltage) were adjusted by $-10 \mathrm{mV}$ to approximately account for liquid junction potential. For example, a recorded AP peak of $30 \mathrm{mV}$ would be reported as $20 \mathrm{mV}$ and a recorded RMP of $-60 \mathrm{mV}$ would be reported as $-70 \mathrm{mV}$.

\section{Computational modeling}

\section{Single neuron model}

We built a conductance-based neuron model to help understand observed results in relation to their underlying biophysical mechanisms. While tSPNs do possess dendrites, their dendritic arborizations are relatively simple. We therefore assume that ganglionic cells are electrotonically compact, and that a single-compartment model can replicate all essential physiologic properties observed in experiments. All currents included in the model have been observed in rodent sympathetic ganglia (Galvan and Sedlmeir, 1984; Sacchi et al., 1995; Jobling and Gibbins, 1999; Rittenhouse and Zigmond, 1999) and transcript expression in mouse thoracic ganglia has recently been confirmed by a single-cell RNA sequencing study (Furlan et al., 2016).

The model is based on a model of bullfrog paravertebral sympathetic ganglia (Wheeler et al., 2004), which represents the most complete available computational model of a paravertebral neuron. From this model the following conductances were taken: a fast sodium current, $I_{\mathrm{Na}}$; a delayed-rectifier potassium current, $\mathrm{I}_{\mathrm{Kd}}$; a slow and noninactivating potassium current, $\mathrm{I}_{\mathrm{M}}$; and a voltageindependent leak current, $\mathrm{l}_{\text {leak }}$. Additional conductances were added from models derived in other species. These
Table 1. Model parameters

\begin{tabular}{lll}
\hline Current & $\mathrm{G}_{\max }(\mathrm{nS})$ & $\mathrm{E}_{\mathrm{rev}}(\mathrm{mV})$ \\
\hline $\mathrm{I}_{\mathrm{Na}}$ & 300 & 60 \\
$\mathrm{I}_{\mathrm{CaL}}$ & 1.2 & 120 \\
$\mathrm{I}_{\mathrm{Kd}}$ & 2000 & -90 \\
$\mathrm{I}_{\mathrm{M}}$ & 50 & -90 \\
$\mathrm{I}_{\mathrm{KCa}}$ & 50 & -90 \\
$\mathrm{I}_{\mathrm{A}}$ & 50 & -90 \\
$\mathrm{I}_{\mathrm{H}}$ & 1 & -32 \\
$\mathrm{I}_{\text {leak }}$ & 1 & -55 \\
$\mathrm{I}_{\text {imp }}$ & 0 & -15 \\
\hline
\end{tabular}

Maximal conductance and reversal potential for the standard model neuron used for computational analysis. *Note that $\mathrm{I}_{\text {imp }}$ is set to $0 \mathrm{nS}$ as it is only included in simulations concerned with microelectrode impalement.

include the following: a fast transient potassium current, $\mathrm{I}_{\mathrm{A}}$ (Rush and Rinzel, 1995); a hyperpolarization-activated inward current, $I_{h}$ (Kullmann et al., 2016); and a calciumdependent potassium current, $\mathrm{I}_{\mathrm{KCa}}$ (Ermentrout and Terman, 2010). $I_{\mathrm{KCa}}$ depends on intracellular calcium concentration, $\left[\mathrm{Ca}^{2+}\right]$, so a model of persistent calcium current, $\mathrm{I}_{\mathrm{CaL}}$ (Bhalla and Bower, 1993) and somatic calcium dynamics (Kurian et al., 2011) were added as well. Model parameters were then tuned to fit recorded data from the present study.

The membrane voltage, $\mathrm{V}$, is updated according to the equation:

$$
C_{m} \frac{d V}{d t}=-\sum I_{i}-I_{\text {input }}
$$

Membrane capacitance, $\mathrm{C}_{\mathrm{m}}$, was set at $100 \mathrm{pF}$ to approximate the mean in recorded neurons. Each current, $\mathrm{I}_{\mathrm{i}}$, is described by the equation:

$$
I_{i}=G_{i} m^{p} h^{q}\left(V-E_{i}\right)
$$

where $G_{i}$ is the maximal conductance, $E_{i}$ is the reversal potential, and $m$ and $h$ are gating variables for activation and inactivation. A standard model neuron was used to replicate the majority of observed phenomena. Maximal conductances of this standard neuron are indicated in Table 1. The standard model was modified as necessary to fit individual recordings, which comprise a heterogeneous population. The reversal potentials for the various membrane currents are indicated in Table 1.

The activation and inactivation variables $m$ and $h$ are updated by the equation:

$$
\frac{d x}{d t}=\frac{x_{\infty}-x}{\tau_{x}}
$$

The intracellular calcium concentration is updated by:

$$
\frac{d}{d t}\left[\mathrm{Ca}^{2+}\right]=\lambda\left(-\alpha l_{\mathrm{CaL}}-k_{\mathrm{CaS}}\left[\mathrm{Ca}^{2+}\right]\right)
$$

where $\lambda=0.01$ is the ratio of free to bound $\left[\mathrm{Ca}^{2+}\right], \alpha=$ $0.002 \mu \mathrm{M} \cdot \mathrm{ms}^{-1} \cdot \mathrm{pA}^{-1}$ is the conversion factor from current to concentration, and $\mathrm{k}_{\mathrm{CaS}}=0.024 \mathrm{~ms}^{-1}$ is the somatic $\left[\mathrm{Ca}^{2+}\right]$ removal rate. 
Table 2. Basic properties of tSPNs

\begin{tabular}{|c|c|c|c|c|c|}
\hline Property & Mean & SD & $n$ & Min & Max \\
\hline \multicolumn{6}{|l|}{ Membrane properties } \\
\hline Resting membrane potential, $\mathrm{mV}$ & -59.8 & 6.8 & 35 & -50 & -80 \\
\hline Input resistance, $\mathrm{M} \Omega$ & 1044 & 576 & 34 & 246 & 2297 \\
\hline Input conductance, nS & 1.31 & 0.84 & 34 & 0.44 & 4.1 \\
\hline Membrane time constant, ms & 91.5 & 55.5 & 34 & 19 & 234 \\
\hline Capacitance, pF & 89.1 & 26.6 & 34 & 51 & 157 \\
\hline \multicolumn{6}{|l|}{ Threshold } \\
\hline Absolute voltage, $\mathrm{mV}$ & -42.4 & 6.2 & 35 & -29.2 & -58.8 \\
\hline Relative to $\mathrm{V}_{\text {hold }}, \mathrm{mV}$ & 24.5 & 6.2 & 35 & 11.8 & 38.9 \\
\hline Measured rheobase, $\mathrm{pA}$ & 27.5 & 16.5 & 35 & 5 & 70 \\
\hline Calculated rheobase, $\mathrm{pA}$ & 30.7 & 18.2 & 34 & 10.1 & 95.9 \\
\hline \multicolumn{6}{|l|}{ AP } \\
\hline Amplitude, mV & 53.6 & 15.7 & 35 & 23.4 & 92.1 \\
\hline Peak, mV & 11.2 & 16.9 & 35 & -30.8 & 47.0 \\
\hline Half-width, ms & 4.6 & 1.0 & 35 & 2.9 & 7.2 \\
\hline Rise slope, $\mathrm{mV} / \mathrm{ms}$ & 46.6 & 24.1 & 35 & 16.3 & 118 \\
\hline \multicolumn{6}{|l|}{ fAHP } \\
\hline Amplitude, mV & 15.0 & 3.7 & 24 & 6.7 & 21.1 \\
\hline Half-decay, ms & 80.4 & 34.5 & 24 & 28.6 & 152 \\
\hline Duration, ms & 229 & 68 & 24 & 109 & 363 \\
\hline \multicolumn{6}{|l|}{ sAHP } \\
\hline Amplitude, mV & 8.5 & 4.5 & 28 & 2.8 & 18.4 \\
\hline Half-decay, ms & 342 & 211 & 27 & 101 & 1097 \\
\hline \multicolumn{6}{|l|}{$f$-I slope } \\
\hline Maximal, Hz/pA & 0.13 & 0.04 & 35 & 0.06 & 0.22 \\
\hline Sustained, $\mathrm{Hz} / \mathrm{pA}$ & 0.06 & 0.04 & 33 & -0.16 & 0.11 \\
\hline
\end{tabular}

Values of basic properties of tSPNs. SD, standard deviation; $n$, number of observations; Min, minimum value; Max, maximum value.

Impalement simulation To replicate impalement injury, an additional leak conductance was added to the model to simulate microelectrode impalement. This conductance, gimp, was modeled as a non-selective ohmic leak channel with $\mathrm{E}_{\mathrm{imp}}=$ $-15 \mathrm{mV}$. The impalement reversal potential was estimated by solving the Goldman-Hodgkin-Katz equation (Eq. 8), with equal permeabilities of the three major ionic species. This estimate agrees well with estimates of impalement reversal potential in bullfrog ganglia (Brown, 1988). For analysis, model neurons were subjected to a bias current and held at $-70 \mathrm{mV}$, unless otherwise stated. gimp was normally set at $0 \mathrm{nS}$, and was only included where indicated for simulation of impalement.

$$
E_{m}=\frac{R T}{F} \ln \left(\frac{P_{\mathrm{Na}}\left[\mathrm{Na}^{+}\right]_{\text {out }}+P_{K}\left[K^{+}\right]_{\text {out }}+P_{C l}\left[\mathrm{Cl}^{-}\right]_{\text {in }}}{P_{\mathrm{Na}}\left[\mathrm{Na}^{+}\right]_{\text {in }}+P_{K}\left[K^{+}\right]_{\text {in }}+P_{\mathrm{Cl}}\left[\mathrm{Cl}^{-}\right]_{\text {out }}}\right)
$$

Synapse simulation Synaptic input was implemented with equation:

$$
I_{\text {syn }}(t)=A \cdot g_{\text {syn }}(t) \cdot\left(V-E_{\text {syn }}\right)
$$

where $I_{\text {syn }}$ is synaptic current, $A$ is conductance amplitude, and $E_{\text {syn }}$ is the synaptic reversal potential set at 0 $\mathrm{mV}$. Synaptic conductance, $\mathrm{g}_{\mathrm{syn}}$, was calculated from the equation:

$$
g_{s y n}(t)=s \cdot\left(e^{-t / \tau_{d}}-e^{-t / \tau_{r}}\right)
$$

where $\tau_{\mathrm{r}}$ and $\tau_{\mathrm{d}}$ are the rise and decay time constants, respectively, and $\mathrm{s}$ is a scaling factor to normalize the amplitude to $1 \mathrm{nS}$. Equations were adapted from Springer et al. (2015). Rise and decay time constants were 1 and 15 $\mathrm{ms}$, respectively, as estimated from voltage clamp recordings of spontaneous synaptic activity.

Code accessibility Source code for all simulation and analysis are available online at https://github.com/pinewave/tSPN and ModelDB (Hines et al., 2004, accession \#245926). Simulation and analysis scripts were written in Python 2.7.10 and executed in PyCharm (CE 2017.1.2) on macOS 10.12.3 with a 1.7-GHz processor. Scripts were also translated into MATLAB code and executed on Windows 10 with a $2.4-\mathrm{GHz}$ processor. All differential equations were integrated using an Exponential Euler method with a time step of $0.1 \mathrm{~ms}$ (Prinz et al., 2004).

\section{Experimental design and statistical analysis}

The present study used a descriptive design. Statistical analyses were performed in Microsoft Excel. Basic properties are presented as mean \pm SD in Table 2. Correlations were determined by Pearson's correlation coefficient, $r$. A two-tailed $t$ test was used to calculate each $p$ value. To control for 30 multiple comparisons and maintain an experiment-wise $\alpha=0.05$, a Šidák corrected $\alpha=0.0017$ was used to assign statistical significance. In some cases, parameter pairs with moderate values of $r$, $(|r|>0.4)$ failed to reach significance as a result of intrinsic variability inherent within this data. Such correlations are reported as moderate, and should be interpreted cautiously. Exact $r, R^{2}$, and $p$ values are presented in Table 3 . 
Table 3. Selected correlations between tSPN parameters

\begin{tabular}{|c|c|c|c|c|c|}
\hline & & $r$ & $R^{2}$ & $n$ & $p$ \\
\hline \multicolumn{6}{|c|}{ Membrane properties } \\
\hline $\mathrm{R}_{\text {in }}$ & $\tau_{\mathrm{m}}$ & 0.84 & 0.70 & 34 & $6.2 \times 10^{-10 *}$ \\
\hline$\tau_{\mathrm{m}}$ & $\mathrm{C}_{\mathrm{m}}$ & 0.40 & 0.16 & 34 & 0.020 \\
\hline \multicolumn{6}{|l|}{ Rheobase } \\
\hline Calculated $I_{\text {rheo }}$ & Measured $I_{\text {rheo }}$ & 0.82 & 0.68 & 34 & $2.0 \times 10^{-9 *}$ \\
\hline Calculated I rheo & $\tau_{\mathrm{m}}^{-1}$ & 0.72 & 0.52 & 34 & $1.5 \times 10^{-6 *}$ \\
\hline Calculated $I_{\text {rheo }}$ & $\mathrm{C}_{\mathrm{m}}$ & 0.06 & 0.00 & 34 & 0.73 \\
\hline \multicolumn{6}{|l|}{ Firing frequency } \\
\hline$f_{\max }$ at $100 \mathrm{pA}$ & $\mathrm{R}_{\text {in }}$ & 0.58 & 0.33 & 30 & $0.00086^{*}$ \\
\hline$f_{\text {sus }}$ at $100 \mathrm{pA}$ & $\mathrm{R}_{\text {in }}$ & 0.21 & 0.05 & 26 & 0.29 \\
\hline$f_{\text {sus }}-1$ slope & $\mathrm{R}_{\mathrm{in}}$ & 0.29 & 0.09 & 32 & 0.10 \\
\hline$f_{\text {sus }}{ }^{-I}$ slope & Calculated $I_{\text {rheo }}$ & -0.24 & 0.06 & 32 & 0.19 \\
\hline$f_{\text {sus }}{ }^{-1}$ slope & $\tau_{\mathrm{m}}$ & 0.26 & 0.07 & 32 & 0.15 \\
\hline$f_{\text {sus }}{ }^{-I}$ slope & $\mathrm{C}_{\mathrm{m}}$ & -0.07 & 0.00 & 32 & 0.70 \\
\hline \multicolumn{6}{|l|}{ AHP } \\
\hline fAHP half-decay & fAHP duration & 0.84 & 0.70 & 24 & $3.0 \times 10^{-7 *}$ \\
\hline fAHP half-decay & $\mathrm{R}_{\mathrm{in}}$ & 0.34 & 0.12 & 24 & 0.10 \\
\hline fAHP half-decay & $\mathrm{C}_{\mathrm{m}}$ & 0.15 & 0.02 & 24 & 0.47 \\
\hline fAHP half-decay & $\tau_{\mathrm{m}}$ & 0.43 & 0.18 & 24 & 0.036 \\
\hline fAHP half-decay & Calculated $I_{\text {rheo }}$ & -0.36 & 0.13 & 24 & 0.083 \\
\hline fAHP half-decay & $f_{\max }$ at $2 \cdot I_{\min }$ & -0.66 & 0.43 & 19 & 0.0022 \\
\hline fAHP half-decay & $f_{\text {sus }}$ at $2 \cdot I_{\min }$ & -0.42 & 0.18 & 12 & 0.17 \\
\hline
\end{tabular}

Selected correlations reported in results. $r$, Pearson's correlation coefficient; $R^{2}$, coefficient of determination; $n$, number of observations; $p$ values calculated from two-tailed $t$ test. Asterisk indicates statistically significant correlation at Šidák corrected $\alpha<0.0017$. $\mathrm{R}_{\text {in }}$, input resistance; $\tau_{\mathrm{m}}$, membrane time constant; $\mathrm{C}_{\mathrm{m}}$, membrane capacitance; $I_{\text {rheo }}$, rheobase current; $\mathrm{V}_{\text {hold }}$, holding voltage; $g_{\mathrm{in}}$, input conductance; $V_{\text {th }}$, threshold voltage; $f_{\text {max }}$, maximal IFR; $f_{\text {sus }}$, sustained firing rate; $I_{\min }$, minimal suprathreshold current.

\section{Results}

\section{Thoracic ganglia composition}

Postganglionic neurons have been shown to be either adrenergic or cholinergic (Jobling and Gibbins, 1999; Jänig, 2006). to assess neurotransmitter identity throughout the sympathetic chain, we used a choline-acetyltransferase (ChAT) transgenic mouse which fluorescently labels putative cholinergic postganglionic neurons (ChAT::eGFP), and coimmunolabelled tissue with an antibody to $\mathrm{TH}$ to label putative adrenergic neurons. Neurons were counted from stellate (T1 and T2) to $\mathrm{T} 13$ ganglia. We found that $\mathrm{TH}^{+}$ neurons comprised $>97 \%$ of the population and no ganglion contained $>6 \%$ presumptive cholinergic neurons. This agrees with prior findings in rodent thoracic ganglia which found few cholinergic neurons (Schäfer et al., 1998; Jobling and Gibbins, 1999; Masliukov and Timmermans, 2004; Schütz et al., 2015; see also Furlan et al., 2016). This indicates that cholinergic neurons in thoracic ganglia are rare. We therefore assume that a large majority of recorded cells were adrenergic.
As the majority of electrophysiological recordings focused on T5, diameter and number of TH-IR cells were examined in T5 ganglia in a separate sample from six adult mice (Fig. 1C). The mean number of TH-IR neurons counted in T5 ganglia was $247 \pm 127$ (ranging from 106 to 418). tSPNs had a mean cell diameter of $23.8 \pm 5.4 \mu \mathrm{m}$ with cell size distribution shown in Figure $1 D$. These values are smaller than those reported previously (31.0 $\pm 1.2 \mu \mathrm{m}$; cf. Jobling and Gibbins, 1999). Differing methodology may explain this discrepancy. The aforementioned study measured the diameter of dyefilled cells after microelectrode impalement, which would preferentially target larger neurons sustained $\mathrm{f}-\mathrm{I}$ slope but not maximal f-I slope (Brown, 1981).

\section{Passive membrane properties}

Whole-cell patch-clamp recordings were acquired from 35 tSPNs obtained from 30 adult mice. Basic cellular properties are summarized in Table 2. The distribution of resting membrane potential is shown in Figure $2 A$. Input resistance $\left(R_{\text {in }}\right)$ and membrane time constant $\left(\tau_{m}\right)$ were, on 

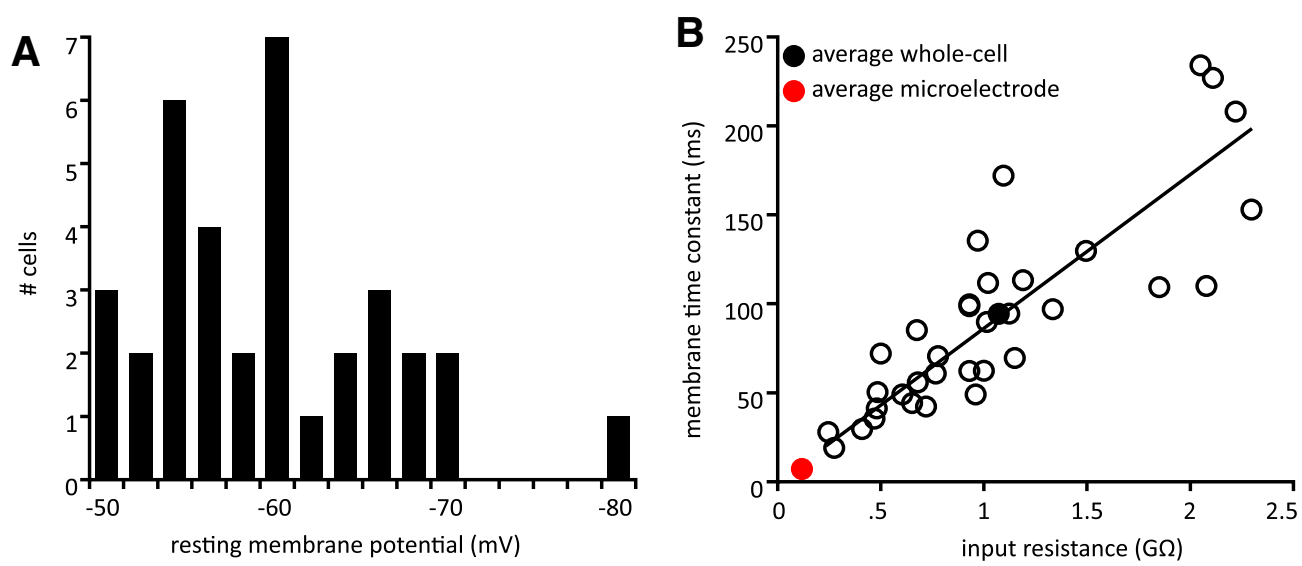

C
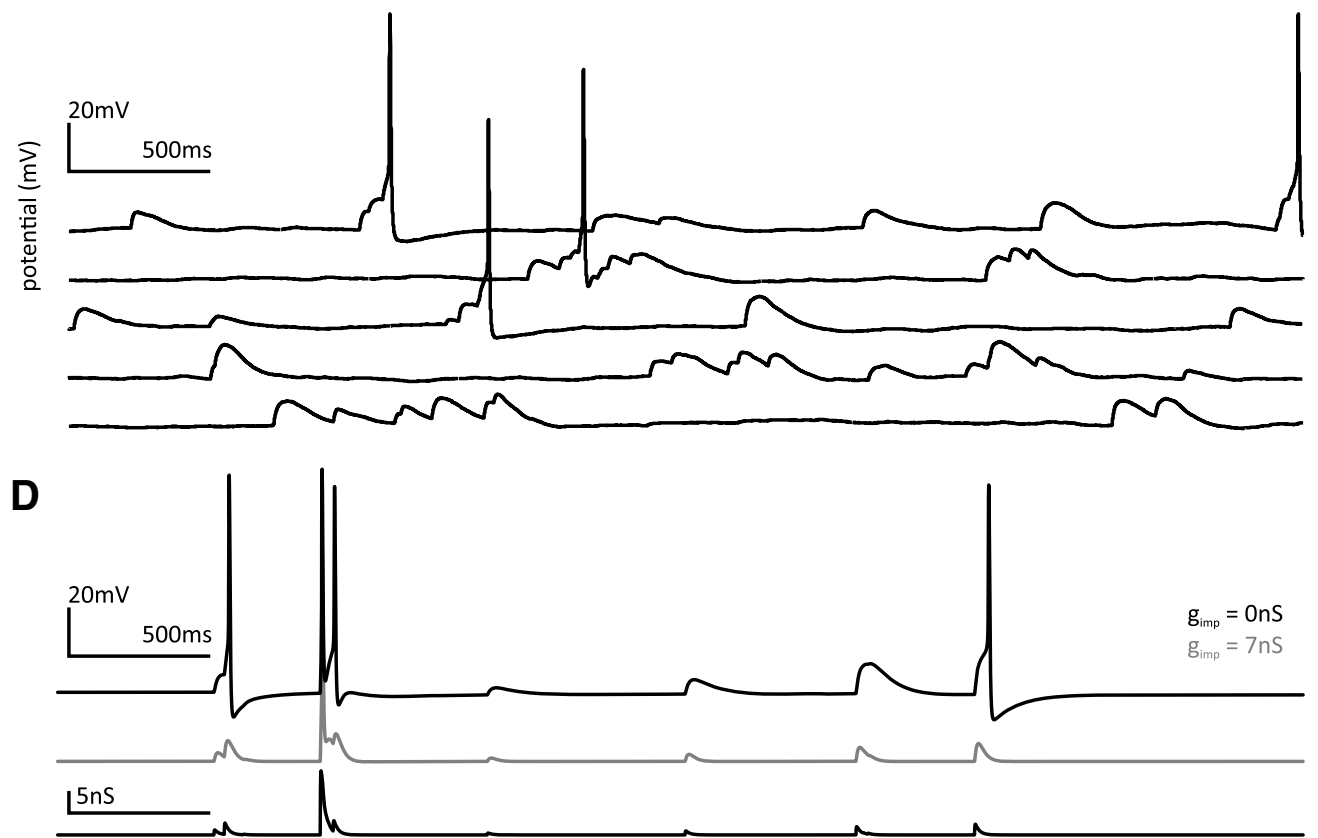

Figure 2. Passive membrane properties. $\boldsymbol{A}$, Histogram showing distribution of resting membrane potential values. $\boldsymbol{B}$, Input resistance is highly correlated with membrane time constant. Solid line indicates linear least-squares fit. Filled black circle represents population mean. Red filled circle represents population mean from (Jobling and Gibbins, 1999). C, Example of synaptic summation leading to AP recruitment in a particularly active recording. Shown is a raster of epochs of spontaneous synaptic activity. Cell resting membrane potential was $-60 \mathrm{mV}$. In this neuron, a $\tau_{\mathrm{m}}$ of $109 \mathrm{~ms}$ led to comparably long EPSP membrane voltage decay $\tau$. Vertical scale bar is $20 \mathrm{mV}$; horizontal scale bar is $500 \mathrm{~ms}$. $\boldsymbol{D}$, Top, Model neuron subjected to simulated synaptic input fires in response to synaptic summation. Middle, If an impalement conductance is added, synaptic summation is no longer effective. Bottom, Simulated $g_{\text {syn }}$ used to generate voltage traces. Horizontal scale bar is $500 \mathrm{~ms}$; vertical scale bars are $20 \mathrm{mV}$ and $5 \mathrm{nS}$, respectively.

average, an order of magnitude higher than values recorded using microelectrode recordings in mouse (Jobling and Gibbins, 1999; Fig. 2B) and guinea pig (Blackman and Purves, 1969) thoracic ganglia. $\mathrm{R}_{\text {in }}$ was strongly correlated with $\tau_{\mathrm{m}}$ (Fig. $2 B$ ), but not cell capacitance $\left(\mathrm{C}_{\mathrm{m}}\right)$, an estimate of cell size. This indicates that membrane resistivity, but not cell size, is primarily responsible for the variability seen in resistance measures (Gustafsson and Pinter, 1984). $C_{m}$ was also moderately correlated with $\tau_{\mathrm{m}}$. A summary of correlation parameters is provided in Table 3.

One impact of larger $\tau_{\mathrm{m}}$ is longer duration spontaneous EPSPs (sEPSPs) and consequently greater capacity for temporal summation. Spontaneous synaptic activity is often observed in whole-cell recordings, including instances of sEPSP summation that lead to recruitment of APs (Fig. 2C). In this neuron, a $\tau_{\mathrm{m}}$ of $109 \mathrm{~ms}$ led to comparably long sEPSP membrane voltage decay $\tau$.

To explore the impact of preserved passive membrane properties on synaptic summation, we implemented a synaptic conductance in the computational model. A template conductance was constructed with Poissondistributed events whose amplitudes and mean frequency match values from whole-cell voltage clamp recordings. This template conductance was used to stimulate a standard model neuron (Fig. 2D, top trace) and a model neuron with simulated microelectrode impalement injury (middle trace). In the intact cell, synaptic events are larger 

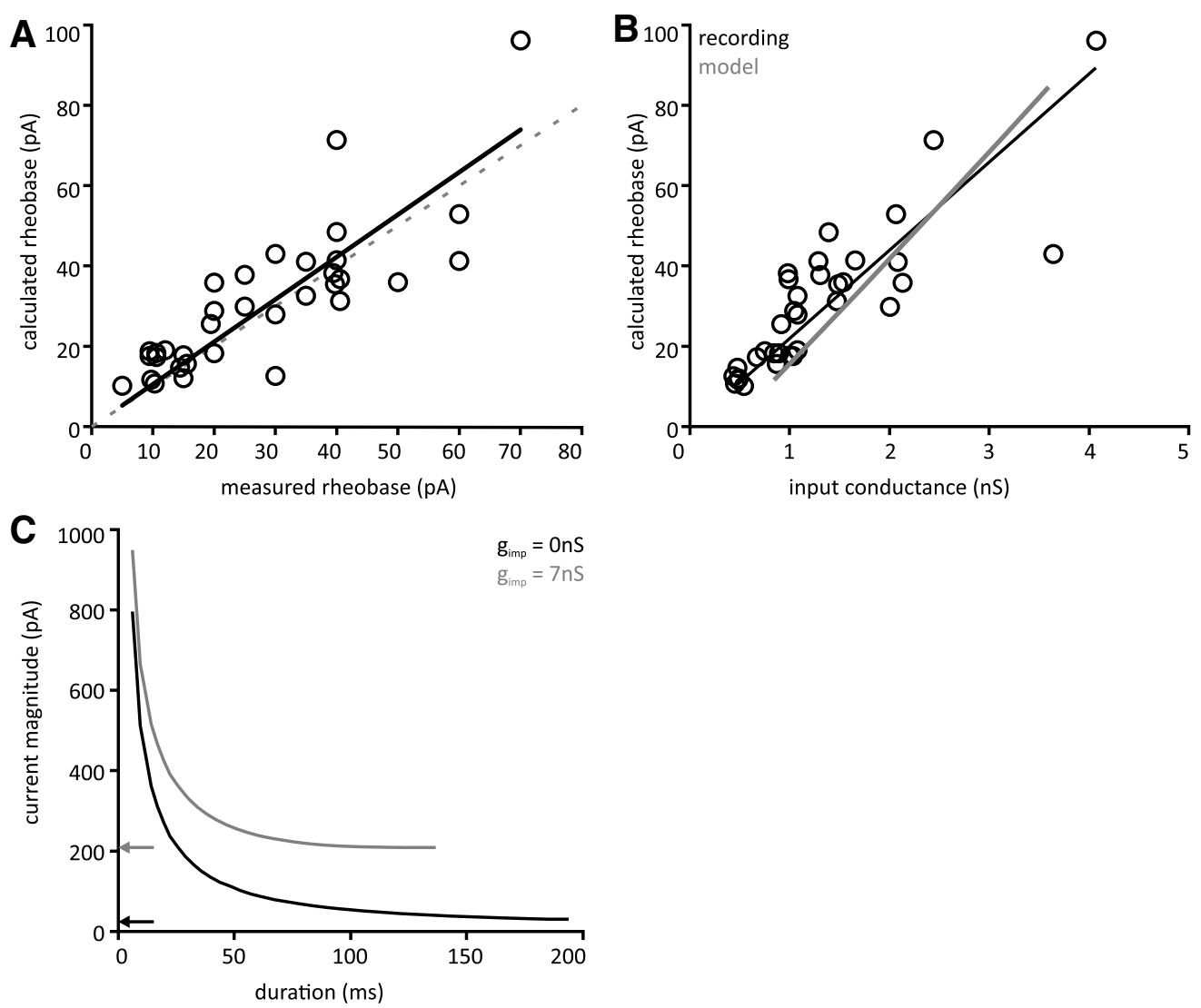

Figure 3. Factors affecting rheobase. $\boldsymbol{A}$, There is a strong correlation between measured rheobase and calculated rheobase and the two values are approximately equal. This suggests that rheobase is predominantly governed by ohmic phenomena. Dashed line is line of identity. $\boldsymbol{B}$, Calculated rheobase was well correlated with input conductance in recorded neurons, open circles. Gray line represents the rheobase versus input conductance relationship for a single model neuron chosen to fit experimental data. Standard model cell with $\mathrm{G}_{\mathrm{M}}=20 \mathrm{nS}$ and $\mathrm{G}_{\mathrm{A}}=15 \mathrm{nS}$. $\boldsymbol{A}, \boldsymbol{B}$, Solid line represents least squares regression. $\boldsymbol{C}$, Strength-duration curves for model neurons. Black, standard model cell with no impalement conductance. Black arrow indicates rheobase. Gray, standard cell with $\mathrm{g}_{\mathrm{imp}}=7 \mathrm{nS}$, comparable to a microelectrode recording. Gray arrow indicates much higher rheobase for impaled cell.

in amplitude and synaptic summation can lead to cell recruitment. In the model neuron with simulated impalement, AP recruitment was observed only in response to the largest single synaptic event.

\section{Rheobase}

The current required to depolarize a cell from its holding potential to firing threshold (rheobase) was examined in 35 cells by injecting long duration (1.5-3 s) pulses through patch electrodes. to control for the possible influence of a variable resting membrane potential on rheobase, tonic bias current was injected to hold cells at approximately $-70 \mathrm{mV}$ before rheobase estimation. Fluctuations in membrane voltage made it difficult to precisely set holding potential before injected current steps, and values ranged from -56 to $-83 \mathrm{mV}$. We compared actual holding voltage against rheobase to determine whether this variability altered rheobase estimation. Rheobase was not correlated with holding potential.

Voltage threshold was assessed at minimal suprathreshold current intensity. Assuming cell depolarization is governed by Ohmic or non-rectifying processes, the ratio of relative voltage threshold to input resistance would predict rheobase (Gustafsson and Pinter, 1984). Indeed, measured and calculated rheobase are well correlated (Fig. 3A; Table 3) and approximately equal, indicating that rectifying currents do not play a major role in determining rheobase for the population. However, deviation of calculated rheobase values above and below those predicted by ohmic processes support a role for voltage-dependent conductances (Gustafsson and Pinter 1984). Values of measured and calculated rheobase are presented in Table 2. As calculated rheobase provides a more precise index of excitability, further analysis focuses on this parameter.

Calculated rheobase current was strongly correlated with input conductance, $g_{\text {in }}=\mathrm{R}_{\text {in }}{ }^{-1}$ (Fig. $3 B$ ), and moderately correlated with the inverse of time constant, $\tau_{\mathrm{m}}{ }^{-1}$, but was uncorrelated with capacitance. A summary of correlation parameters is provided in Table 3 .

We further investigated the relationship between input conductance and rheobase in a model cell. We adjusted $g_{\text {leak }}$ to vary input conductance of a model neuron over most of the range observed in recorded neurons (0.5-3 nS). Bias current was adjusted to hold the model cell at $-70 \mathrm{mV}$. The rheobase was then calculated for each value of input conductance by using a binary search algorithm to find the minimal injected current which produces a 
spike (Fig. 3B, gray line). The results show that there is a deterministic relationship between rheobase and input conductance that can help to explain some of the correlation observed in recorded neurons. However, given the variability of rheobase measures in recorded cells with comparable values for input conductance, it is clear that input conductance alone does not fully explain the range of rheobase values observed in recorded neurons.

Rheobase values were $80-90 \%$ lower than values estimated in tSPNs previously with microelectrode recordings in both mouse and guinea pig (Blackman and Purves, 1969; Jobling and Gibbins, 1999). Reduced rheobase values indicate that tSPNs are much more excitable than previously considered. To more fully explore the influence of microelectrode impalement on cell excitability, we constructed strength-duration curves for model cells. In a standard model cell, the strength-duration curve follows a characteristic inverse curve. After implementation of an impalement conductance consistent with a microelectrode recording, rheobase is increased $\sim 8$-fold (Fig. 3C). This is consistent with the discrepancy between our experimental findings and the aforementioned studies using microelectrodes.

\section{Repetitive firing}

Increasing current steps were delivered to assess repetitive firing properties from a holding potential of approximately $-70 \mathrm{mV}$. All cells $(n=35)$ were capable of repetitive firing in response to sustained current injection. This contradicts an earlier report that tSPNs fire phasically in response to depolarization (Jobling and Gibbins, 1999). Figure $4 A$ shows an example of a recorded cell which fires repetitively at progressively higher frequency in response to increasing depolarizing current steps (top). A model neuron that used known voltage-dependent conductances for paravertebral sympathetic neurons and incorporated values for input conductance obtained from our whole-cell recordings was able to replicate repetitive firing (Fig. 4A, bottom).

$f-I$ relations were obtained by plotting the maximal (initial) and sustained firing rate versus injected current magnitude. Figure 4Bi,ii shows the maximal and sustained, respectively, $f-I$ curves for all cells. Maximal IFR did not exceed $28 \mathrm{~Hz}$, while sustained firing rate did not exceed $17 \mathrm{~Hz}$ for the highest steps given. $f$-I curves were approximately linear. to determine the role that input conductance plays in determining $f-\mathrm{I}$ relations in tSPNs, we selected a model neuron that matches the experimental $f-$ l curves and then systematically changed input conductance by varying $g_{\text {leak }}$ from 0 to $3 \mathrm{nS}$. Of note, varying input conductance also changes holding potential so to remain consistent with experimental protocol, each model neuron was subjected to a different holding current to hold the initial voltage at $-70 \mathrm{mV}$. Figure 4Biii, iv demonstrates that altering $g_{\text {leak }}$ can shift the $f$-I curve, but it does not appear to change the $f$-I slope. Thus, input conductance cannot fully account for the range of $f-I$ curves observed. To determine whether other model parameters are capable of changing $f$-I slope, we systematically varied each parameter and observed its influence on maxi- mal and sustained $f$-l curves. Most notably, $\mathrm{C}_{\mathrm{m}}$ appears to influence the slope of the maximal $f$-I curve while $\mathrm{G}_{\mathrm{CaL}}$ and $G_{K C a}$ impact the slope of the sustained $f-I$ curve. Other model parameters $\left(\mathrm{G}_{\mathrm{Na}}, \mathrm{G}_{\mathrm{K}}, \mathrm{G}_{\mathrm{M}}, \mathrm{G}_{\mathrm{A}}, \mathrm{G}_{\text {leak }}\right)$ are able to shift $f-I$ curves without significantly altering slope. Thus, we are able to match any realistic $f$-I curve by adjusting model parameters, which implies that a host of intrinsic cellular properties are responsible for the range of $f$-I curves we observed.

Slope for both maximal and sustained $f-I$ curves was calculated as a measure of excitability (Zimmerman and Hochman, 2010). In short, a cell with a higher $f$-I slope would respond to an incremental change in current with a higher change in firing frequency. In this way, $f-I$ slope can be thought of as the gain between input and output of a neuron. Values for maximal and sustained $f-I$ slope are given in Table 2.

We assessed the role of variations in $\mathrm{R}_{\text {in }}$ and rheobase in cell excitability based on $f$-I slope measures. Maximal firing rate at $100-\mathrm{pA}$ current injection was significantly correlated with $\mathrm{R}_{\mathrm{in}}$. Maximal $f$-I slope was moderately correlated with $\mathrm{R}_{\text {in }}$ (Fig. 4C), and moderately and negatively correlated with calculated rheobase (Fig. 4D). No such relationship was found for $\tau_{m}$ or $C_{m}$. A summary of correlation parameters is provided in Table 3. Cells with lower rheobase and higher $R_{\text {in }}$ had higher $f-$ I slopes, suggesting that Ohmic properties contribute to the $f-I$ response.

\section{Impalement simulation}

The discrepancy between observations of phasic and repetitive firing likely arises as a result of leak introduced by microelectrode impalement (Springer et al., 2015). We undertook additional modeling to test whether an impalement injury can convert repetitive to phasic firing. An additional impalement conductance, $g_{i m p}$, was added to a standard model cell. Reversal potential of $g_{i m p}$ was set at $-15 \mathrm{mV}$. We explored the relationship between $\mathrm{g}_{\mathrm{imp}}$ and firing type over a range of conductance and current injection combinations (Fig. 5). For a given set of $g_{i m p}$ and injected current, a model cell was characterized as nonfiring $(N)$, phasic firing $(P)$, or repetitively firing $(R)$. Setting $\mathrm{g}_{\mathrm{imp}}$ to $7 \mathrm{nS}$ results in an input resistance of $\sim 100 \mathrm{M} \Omega$, the mean value of input resistance reported by Jobling and Gibbins (1999). With this level of microelectrode leak, non-firing was observed in response to subthreshold current injection (Fig. 5Ai), and phasic firing was observed in response to suprathreshold current injection over the range of values tested by Jobling and Gibbins (Fig. 5Aii). However, when $g_{i m p}$ was set at $0 \mathrm{nS}$, analogous to a whole-cell recording, repetitive firing was observed instead (Fig. 5Aiii).

Prior studies have reported that phasic firing sympathetic neurons could instead fire repetitively if $I_{M}$ was blocked (Brown and Adams, 1980; Cassell et al., 1986). To test this, we blocked $\mathrm{I}_{\mathrm{M}}$ in our model cell by setting $\mathrm{g}_{\mathrm{M}}$ to $0 \mathrm{nS}$. This change completely eliminated phasic firing in the model, and only non-firing (Fig. 5Aiv) or repetitive firing was observed (Fig. 5Av).

To more extensively characterize this phenomenon, the boundaries between each of the three firing types were 

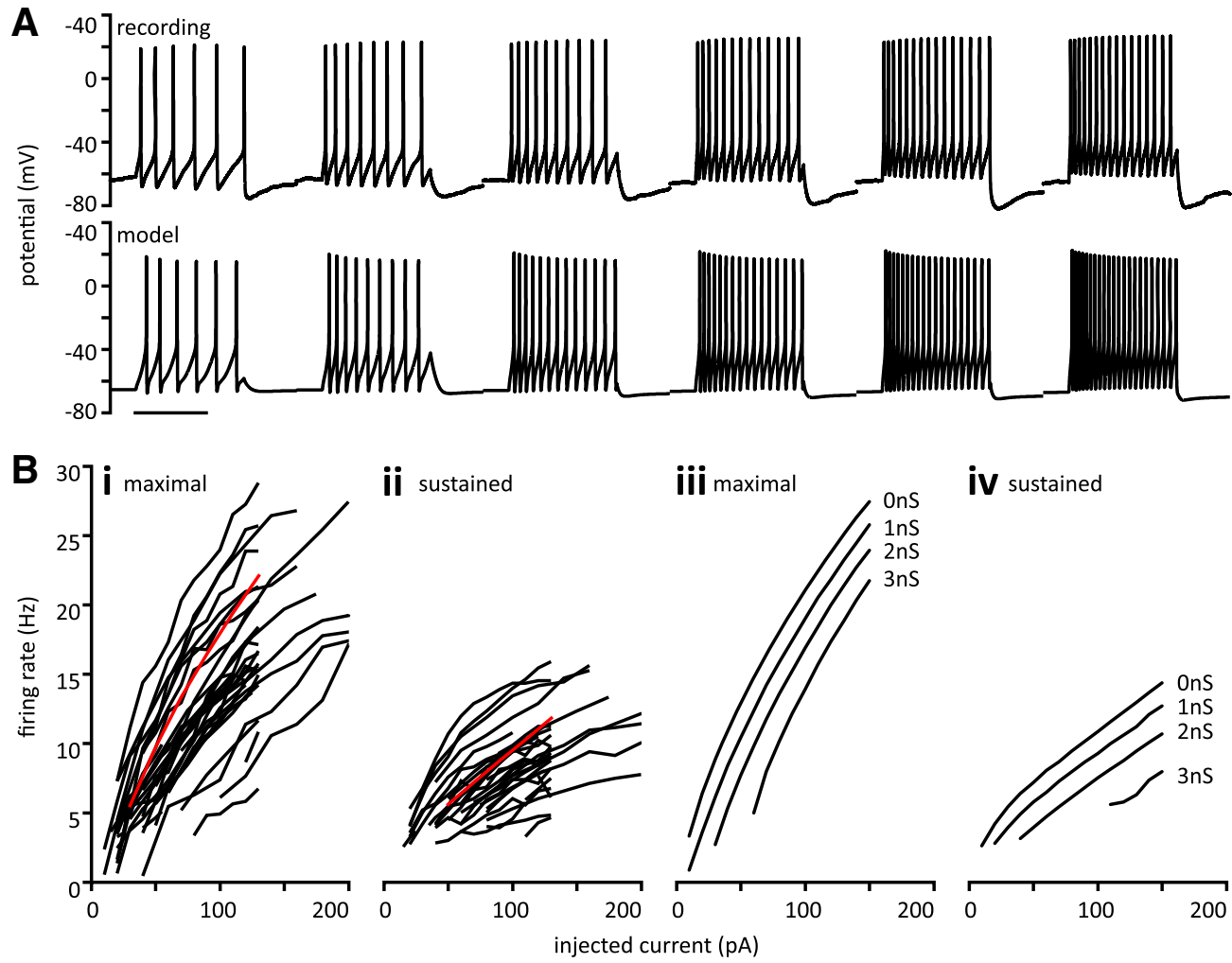

iv sustained
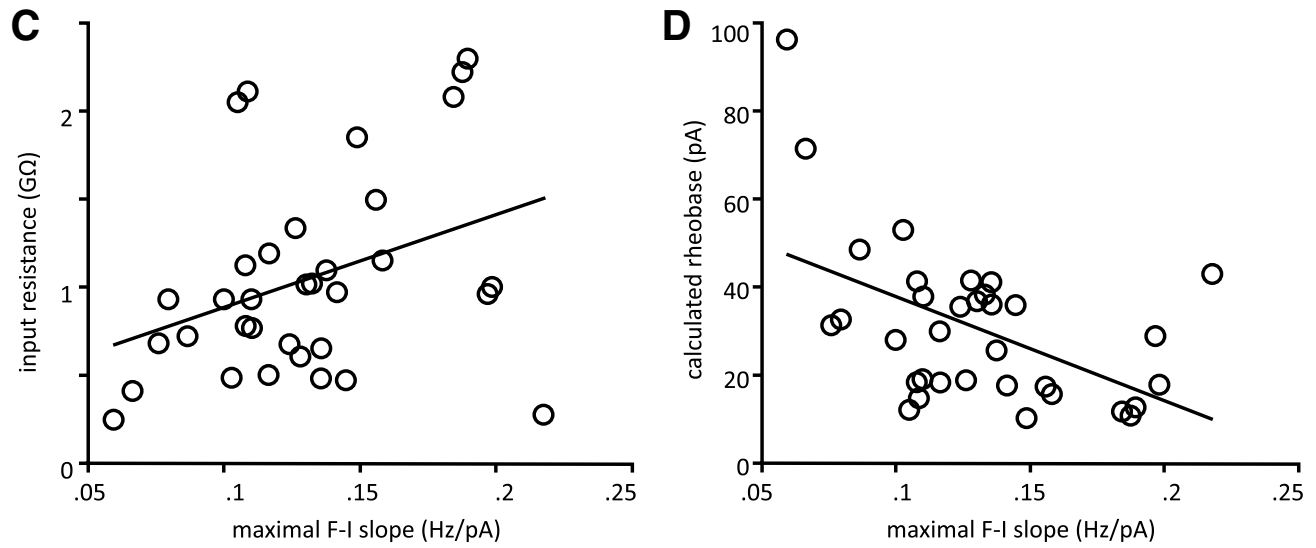

Figure 4. tSPNs exhibit repetitive firing. $\boldsymbol{A}$, Top, Representative trace from a tSPN showing increases in repetitive firing frequency in response to increasing current steps. Bottom, Model neuron also showing repetitive firing. Standard model with $G_{M}=30, G_{K C a}=70$, $\mathrm{G}_{\mathrm{A}}=80, \mathrm{G}_{\text {leak }}=2 \mathrm{nS}$. Injected current from left to right in both recorded neuron and model is 30, 50, 70, 90, 110, 130 pA. Scale bar is 1 s. $\boldsymbol{B}, f-I$ relations for recorded and model neurons. $\boldsymbol{i}$, Maximal IFR is plotted versus injected current for all cells. ii, Same as $\boldsymbol{C i}$ with sustained firing rate. Red line in $\mathrm{i}$ and ii is maximal and sustained $f$-l curve from model neuron in $\boldsymbol{A}$. iii, Maximal $f$-I curve from a model neuron in which $g_{\text {leak }}$ was adjusted from 0 to $3 \mathrm{nS}$. Note: as varying input conductance also changes holding potential, each model neuron was subjected to a different holding current to hold the initial voltage at $-70 \mathrm{mV}$. Also note that $g_{\text {leak }}$ is distinct from $g_{\text {imp. }}$ iv, Corresponding sustained $f$-I curves. Model parameters other than $g_{\text {leak }}$ are the same as in $\boldsymbol{A}$. C, Maximal $f$-I slope is positively correlated with input resistance. $\boldsymbol{D}$, Maximal $f$-I slope is negatively correlated with calculated rheobase.

identified using a binary search algorithm. In the case where $I_{M}$ is included in the model (Fig. $5 B$ ), there was a rapid transition from repetitive to phasic firing as $g_{i m p}$ is increased. When $I_{M}$ is removed (Fig. 5C), the phasic firing region $(\mathrm{P})$ disappears.

\section{SRA}

Implicit in the observation that sustained firing rates were lower than initial observed frequencies is that all cells displayed SRA, or a decrease in firing rate over time.
We were able to replicate SRA in our model (Fig. 6A). The time course of adaptation consists of a fast and a slow phase (Fig. 6B).

The difference between the initial firing rate and the sustained firing rate becomes more pronounced as injected current is increased in all cells. This can be illustrated by comparing the maximal $f-I$ curve to the sustained $f-I$ curve in both recorded and model neuron over a range of current injection (Fig. 6C). This relationship between maximal and sustained firing rate is a 

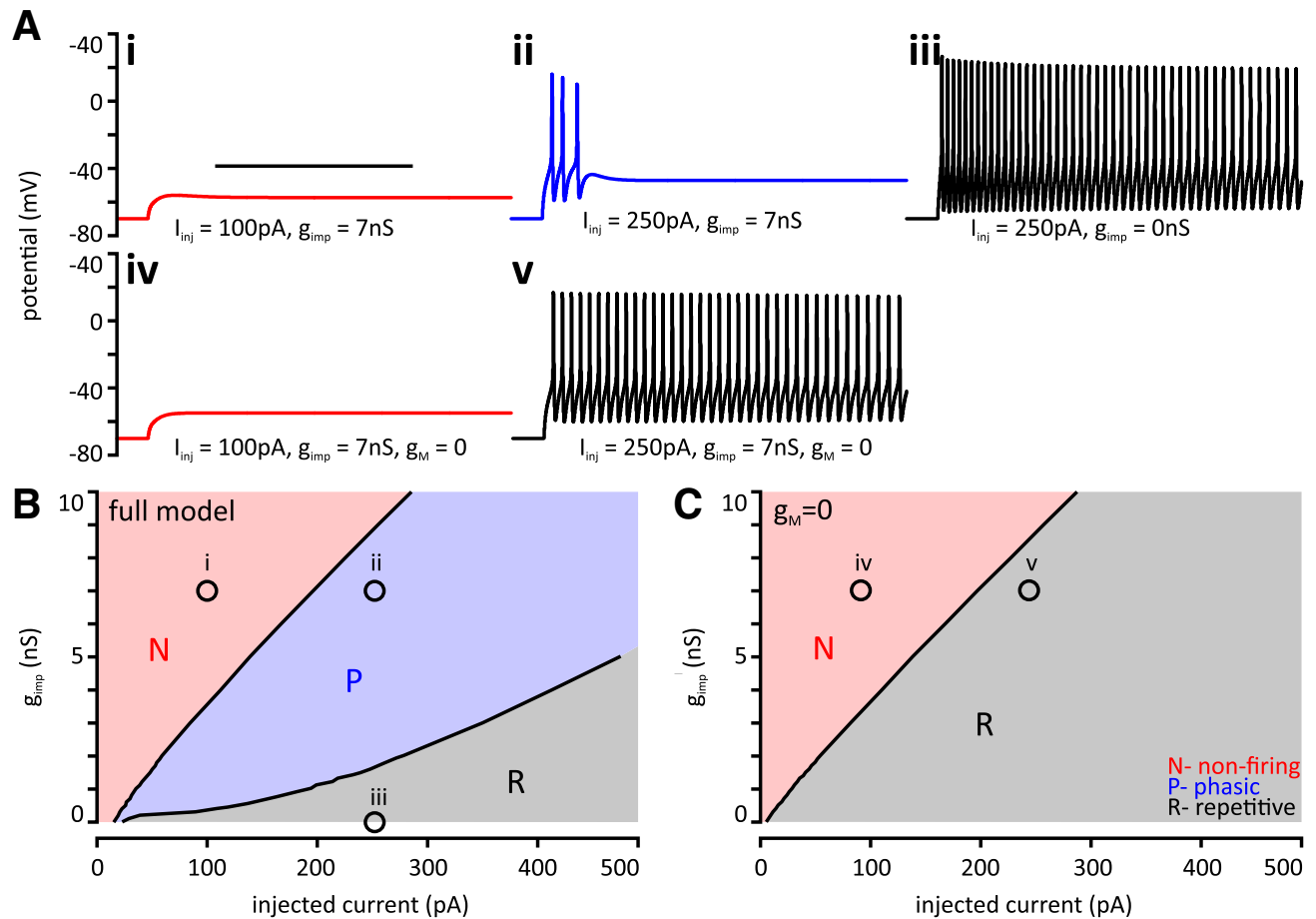

Figure 5. Simulated impalement can alter firing properties. $\boldsymbol{A}$, Impact of injected current and impalement conductance, $\mathrm{g}_{\mathrm{imp}}$, on firing properties. Voltage response of a model cell to subthreshold (i) and suprathreshold (ii) current injection after $g_{\text {imp }}$ is set to $7 \mathrm{nS}$, analogous to a microelectrode recording. Only phasic firing is observed. iii, Repetitive firing is observed when $g_{i m p}$ is set to $0 \mathrm{nS}$, analogous to a whole-cell recording. When $\mathrm{g}_{\mathrm{M}}$ is removed from the model, the same parameters used in $\boldsymbol{i}$, ii lead to non-firing (iv) and repetitive firing (v). $\boldsymbol{B}$, Shaded regions indicate the set of all parameters which lead to non-firing $(N$, red), phasic firing $(P$, blue), and repetitive firing ( $R$, black/gray). At $g_{i m p}=0 \mathrm{nS}$, the model neuron transitions rapidly from $\mathrm{N}$ to $\mathrm{R}$, and repetitive firing results from any current injection above $\sim 20 \mathrm{pA}$. At $\mathrm{g}_{\mathrm{imp}}=7 \mathrm{nS}$, the model neuron transitions from $\mathrm{N}$ to $\mathrm{P}$ at around 200-pA current injection, and repetitive firing is not observed for injected current less than $500 \mathrm{pA}$. $\boldsymbol{C}$, same as $\boldsymbol{B}$ with $\mathrm{g}_{\mathrm{M}}$ set to $0 \mathrm{nS}$. Removing $\mathrm{I}_{\mathrm{M}}$ from the model by setting $\mathrm{g}_{\mathrm{M}}=0 \mathrm{nS}$ eliminates phasic firing altogether, i.e., cells transition directly from $\mathrm{N}$ to $\mathrm{R}$ regardless of impalement conductance. Open circles in $\boldsymbol{B}, \boldsymbol{C}$ indicate the $g_{\mathrm{imp}}$ and injected current values used to generate traces in $\boldsymbol{A}$. Standard model with $\mathrm{g}_{\text {leak }}=0.5 \mathrm{nS}$.

common feature of adapting neurons (Benda and Herz, 2003).

Several mechanisms have been proposed to underlie SRA in different neuronal populations including $\mathrm{Na}^{+}$channel inactivation (Miles et al., 2005), fAHP summation (Powers et al., 1999), activation of $\mathrm{I}_{\mathrm{KCa}}$ (Miles et al., 2005) and activation of $I_{M}$ (Yi et al., 2015). We selectively removed conductances from the model and determined which were primarily responsible for SRA (Fig. 6D). Removal of $I_{\mathrm{KCa}}$ preferentially impaired the later phase of adaptation (curve 1) while removal of $I_{M}$ preferentially impaired the early phase of adaptation (curve 2). Removal of both $I_{\mathrm{KCa}}$ and $I_{\mathrm{M}}$ completely eliminated SRA (curve 3). Our model supports the conclusion that the combination of these conductances is necessary to replicate SRA.

\section{AHP}

AHP dynamics play an important role in regulating neuronal firing. Based on decay time, we identified three types of AHP within the thoracic ganglia. These include the fAHP after a single AP, and the sAHP and ultra-slow AHP (usAHP) after multiple APs (Fig. 7A).

Fast post-spike after-hyperpolarization (fAHP) amplitude, half-decay time, and duration were measured at rheobase current injection (Fig. 7Ai). Parameters related to fAHP are summarized in Table 2. Half-decay time was very well correlated with duration and more reliably obtained, so further analysis focused on fAHP half-decay time. fAHP half-decay time was compared to passive membrane properties and rheobase. fAHP half-decay time was not correlated with $R_{i n}, C_{m}$, or rheobase, but was moderately correlated with $\tau_{\mathrm{m}}$. Previous studies have reported an inverse relationship between fAHP duration and firing rate in motoneurons (Brownstone et al., 1992; Stauffer et al., 2007). To determine whether this relationship exists in postganglionic neurons, we plotted fAHP half-decay time versus sustained firing rate at two times the minimal suprathreshold current injection. Note that this corresponds to twice the current magnitude used to estimate fAHP half-decay time. We found that there is indeed a moderate negative correlation between fAHP half-decay time and maximal firing rate (Fig. 7B). fAHP half-decay time was also moderately correlated with sustained $f$-I slope but not $f$-I slope.

sAHPs were also observed following larger depolarizing steps that elicited higher repetitive firing frequencies (Fig. 7 Aii). Only cells displaying obvious sAHP were analyzed ( $n$ $=27$ of 35 ). sAHPs were measured at maximal current injection. Parameters related to SAHP are summarized in Table 2. sAHP half-decay time was four-fold longer on average than fAHP half-decay, but the two were not correlated. To examine the relationship between sAHP 

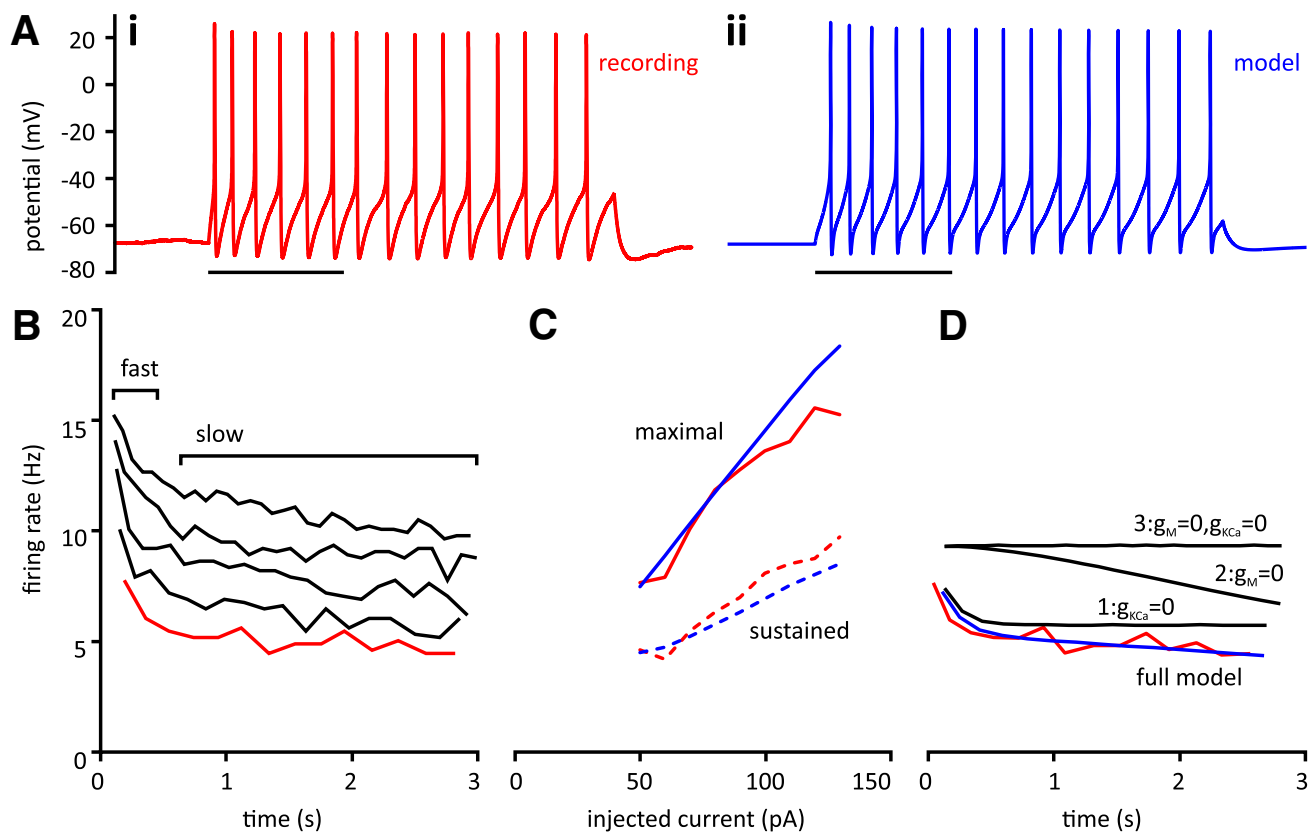

Figure 6. Modeling suggests that SRA in tSPNs depends on both $\mathrm{I}_{\mathrm{M}}$ and $\mathrm{I}_{\mathrm{KCa}}$. Ai, Representative trace showing tSPN response to 50-pA current injection. Note that the interspike interval increases over time, corresponding to a decrease in instantaneous frequency. ii, Trace from a model cell chosen to fit the recording shows similar $S R A$ for $50-p A$ current injection. Maximal conductances are: $G_{\mathrm{Na}}=400 \mathrm{nS}$, $\mathrm{G}_{\mathrm{K}}$ $=3000 \mathrm{nS}, \mathrm{G}_{\mathrm{CaL}}=1.2 \mathrm{nS}, \mathrm{G}_{\mathrm{M}}=40 \mathrm{nS}, \mathrm{G}_{\mathrm{KCa}}=60 \mathrm{nS}, \mathrm{G}_{\mathrm{A}}=80 \mathrm{nS}, \mathrm{G}_{\mathrm{H}}=1 \mathrm{nS}, \mathrm{G}_{\text {leak }}=2 \mathrm{nS}$. Scale bar in both panels is $1 \mathrm{~s}$. B, Instantaneous frequency versus time for the same recorded cell at 50-, 70-, 90-, 110-, and 130-pA current injection (from bottom to top). The 50-pA curve (red) corresponds to the trace in Ai. Fast and slow components of adaptation are indicated. C, Maximal and sustained $f$-I curves match well between recorded and modeled cell over a range of injected currents. Red, maximal (top, solid) and sustained (bottom, dashed) $f$-I curves for the cell in $\boldsymbol{A i}, \boldsymbol{B}$. Blue lines are the corresponding $f$-I curves from the model cell in $\boldsymbol{A i i}$. $\boldsymbol{D}$, Instantaneous frequency versus time curves for the model cell in Aii. The recorded 50-pA curve from $\boldsymbol{B}$ is reproduced for comparison to the analogous curve generated in the model cell in Aii (blue). Black curves numbered 1-3 represent effect of removal of two conductances from the model. Removal of $g_{K C a}$ (curve 1) predominantly influences the slow SRA. Removal of $g_{M}$ (curve 2) predominantly influences the fast SRA. Removal of both (curve 3 ) eliminates SRA. The ordinate axis is shared among $\boldsymbol{B}-\boldsymbol{D}$.

and SRA, we plotted the SAHP half-decay versus the SRA ratio for 27 cells (Fig. $7 C$ ). We found the two parameters were significantly correlated. A summary of correlation parameters for both fAHP and SAHP is provided in Table 3. As with SRA, our computational model showed that $I_{M}$ and $I_{\mathrm{KCa}}$ were capable of reproducing sAHP after repetitive firing (not shown).

Prior work in the rabbit SCG identified a long-lasting AHP following sustained depolarization that was due to the ouabain sensitive $\mathrm{Na}^{+} / \mathrm{K}^{+}$-ATPase (Lees and Wallis, 1974). In the neonatal mouse spinal cord, it has been shown to be due to activation of $\alpha 3 \mathrm{Na}^{+} / \mathrm{K}^{+}$-ATPase (Picton et al., 2017). This AHP is unique in its ability to hyperpolarize a cell membrane beyond the reversal potential of $\mathrm{K}^{+}$. We identified an AHP with a similar time course. We injected depolarizing current to cause the cell to fire repetitively. This repetitive firing led to a steadily increasing hyperpolarization (Fig. 7Aiii). In the example shown, induced epochs of repetitive firing led to a $20-\mathrm{mV}$ membrane hyperpolarization (Fig. 7Aiv). This feature was present in two of 14 cells tested with a current step protocol that would allow for its observation. Of note, the usAHP was observed only in relatively high resistance cells when ATP and GTP were included in the electrode solution. This AHP was also able to achieve a membrane potential of $-101.7 \pm 11.5 \mathrm{mV}$, which is more negative than the calculated $-98 \mathrm{mV} \mathrm{K} \mathrm{K}^{+}$reversal potential. The time course of this hyperpolarization is too long to be due to $I_{M}$ or $I_{\mathrm{KCa}}$.

\section{Subthreshold conductances}

Subthreshold conductances can play an important role in determining cell excitability and firing properties. We evaluated activation of these conductances with current steps that included assessment at hyperpolarized membrane potentials seen during the usAHP.

In response to depolarizing current steps, membrane voltage first followed an exponential time course with subsequent recruitment of voltage-gated conductances that altered the trajectory. In 24 of 35 cells, membrane trajectory exhibited a negative deflection from the exponential trajectory which preceded activation of voltage gated $\mathrm{Na}^{+}$conductance. The observed deflection, or "notch," in membrane led to a delay in the first AP in a train (Fig. 8Ai) and has been described previously in tSPNs (Jobling and Gibbins, 1999). This phenomenon was often observed at a holding potential of $-70 \mathrm{mV}$, and became more pronounced with greater hyperpolarization $(-90 \mathrm{mV})$. This is consistent with activation of the transient, voltage-gated A-type $\mathrm{K}^{+}$current $\left(\mathrm{I}_{\mathrm{A}}\right)$. To test the contribution of $\mathrm{I}_{\mathrm{A}}$ to the notch and delayed firing, we held a model neuron at two different holding potentials and 

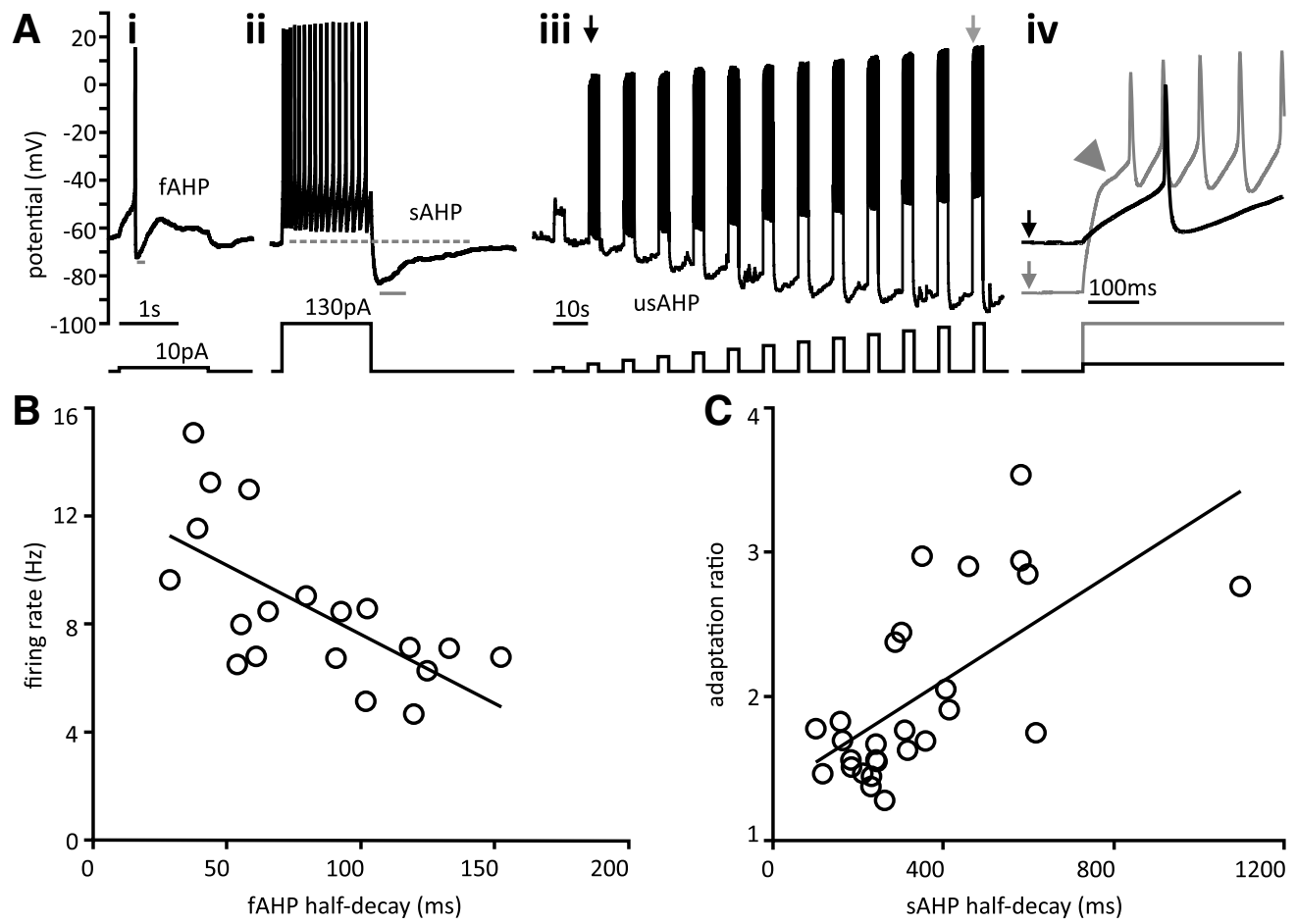

Figure 7. AHP. A, Side by side comparison of three types of AHPs. $\boldsymbol{i}$, fAHP present after single spike. ii, sAHP is present in the same cell only after repetitive firing. The half-decay time of fAHPs and sAHPs are indicated by the gray bar beneath each trace. Scale bar $1 \mathrm{~s}$. iii, Depolarizing current steps (10-130 pA in 10-pA increments) in a different cell showing the progressive hyperpolarization characteristic of the usAHP. Scale bar $10 \mathrm{~s}$. iv, Expanded view of voltage traces in Aiii indicated by vertical arrows. Note that the gray trace is hyperpolarized by $20 \mathrm{mV}$ compared to the black trace and has a characteristic notch (arrowhead) on depolarization. Current injection profile is shown below each trace. $B$, fAHP half-decay was negatively correlated with maximal firing rate at twice the minimal suprathreshold current. $\boldsymbol{C}$, SRA ratio is positively correlated with SAHP half-decay. Black line is the linear regression.

found that the change in trajectory was indeed attributable to de-inactivation of $\mathrm{I}_{\mathrm{A}}$ (Fig. 8Aii; Rush and Rinzel, 1995). Notably, a similar notch was observed in cells displaying usAHP (Fig. 7Aiv), demonstrating that the usAHP leads to a state of membrane hyperpolarization where $I_{A}$ would delay onset of firing.

During hyperpolarizing current injection, a depolarizing voltage "sag" was often observed. When present, a voltage sag was easily detected with membrane hyperpolarization beyond $-100 \mathrm{mV}$ (Fig. 8Bi) but was also observed at less negative hyperpolarization (Fig. $8 \mathrm{Ci}$ ). We found a voltage sag in 17 of 28 cells hyperpolarized to at least $-100 \mathrm{mV}$ from a holding potential of $-70 \mathrm{mV}$. This phenomenon has been previously reported in mouse tSPNs (Jobling and Gibbins, 1999) and other mammalian sympathetic neurons (Cassell et al., 1986) where it has been attributed to the anomalous rectifier, or $\mathrm{H}$-current $\left(\mathrm{I}_{\mathrm{H}}\right)$. To support a role for $I_{H}$, this conductance was implemented in the computational model and was found to reproduce the observed voltage sag (Fig. 8Bii). $\mathrm{I}_{H}$ has also been shown to contribute to a more depolarized membrane potential (Pape, 1996; Lamas, 1998), so we compared resting membrane potential in cells with $(n=17)$ and without $(n=11)$ evidence of $\mathrm{I}_{H}$ but found no significant differences (Student's $t$ test, two-tailed, $p=0.17$ ).

$\mathrm{I}_{\mathrm{H}}$ has also been implicated in post-inhibitory rebound firing (Pape, 1996; Ascoli et al., 2010; Engbers et al., 2011; Ferrante et al., 2017). Sag was seen in 12 of 13 tSPNs exhibiting rebound firing, but rebound firing was only observed when cells were held closer to firing threshold (between -60 and $-50 \mathrm{mV}$; Fig. $8 \mathrm{Ci}$ ) where $\mathrm{I}_{\mathrm{M}}$ has been shown to be responsible for inducing a voltage sag and rebound firing (Constanti and Galvan, 1983). We used a computational model to understand the relative contributions of $I_{H}$ and $I_{M}$ and determined that sag is due to $I_{H}$ for significant hyperpolarizations, and $\mathrm{I}_{\mathrm{M}}$ for more moderate hyperpolarization. Rebound firing can occur in the absence of $I_{H}$ but does not occur in the absence of $I_{M}$ following release from moderate $(\sim 10 \mathrm{mV})$ hyperpolarization, indicating that $\mathrm{I}_{\mathrm{H}}$ is neither necessary nor sufficient to induce rebound firing in tSPNs (Fig. 8Cii).

\section{Discussion}

\section{Reappraisal of physiologic consequence of passive membrane properties}

We obtained high-quality recordings of mouse tSPNs and built a computational model to provide mechanistic insight into their function. Whole-cell recordings preserve membrane properties and provide an accurate representation of tSPN function. This is critically important, as the impalement conductance introduced by microelectrode recordings can change passive membrane properties (Staley et al., 1992; Cymbalyuk et al., 2002; Springer et al., 2015), reduce apparent excitability, underestimate the importance of synaptic convergence (Karila and Horn, 2000; 

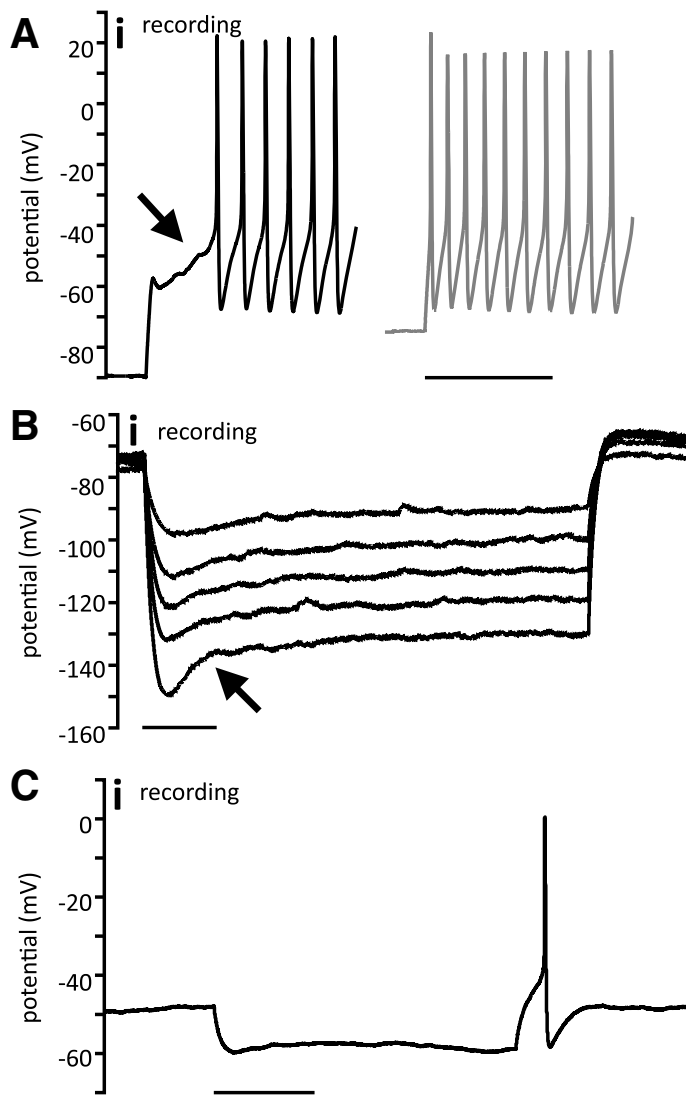
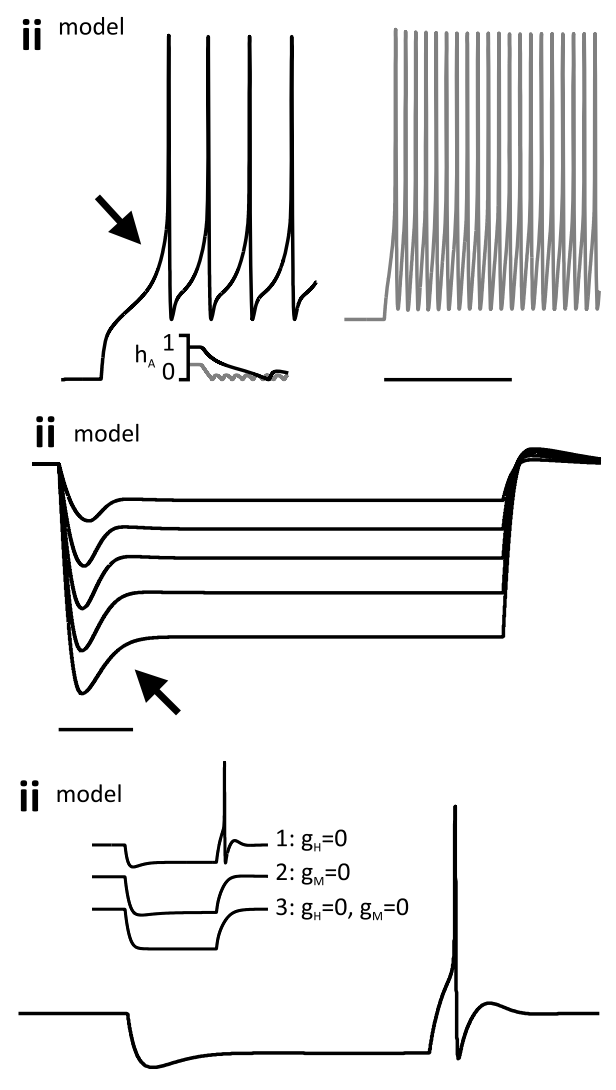

Figure 8. Subthreshold conductances. Ai, A cell depolarized from $-90 \mathrm{mV}$ exhibits a characteristic notch (arrow) accompanied by a delay in spiking (black trace). The same cell depolarized from $-70 \mathrm{mV}$ does not have a notch (gray trace). ii, Model neuron showing comparable results with pre-spike inflection seen only for hyperpolarized trace. Standard model with $\mathrm{G}_{\mathrm{M}}=10 \mathrm{nS}, \mathrm{G}_{\mathrm{KCa}}=10 \mathrm{nS}, \mathrm{G}_{\mathrm{A}}$ $=90 \mathrm{nS}, \mathrm{G}_{\text {leak }}=0 \mathrm{nS}$. Inset, Magnitude of $\mathrm{h}_{\mathrm{A}}$ at onset of current injection shows that $\mathrm{I}_{\mathrm{A}}$ is less inactivated (h⿻ $\mathrm{h}_{\mathrm{A}}$ is higher) at hyperpolarized voltage, and $\mathrm{I}_{\mathrm{A}}$ takes longer to fully inactivate. Scale bars represent $500 \mathrm{~ms}$ for all panels. Bi, Voltage sag, indicated by arrow, on hyperpolarization beyond $-90 \mathrm{mV}$ in a cell held at $-70 \mathrm{mV}$. Note that the effect becomes more pronounced with greater hyperpolarization. ii, Model neuron showing similar sag. Standard model with $\mathrm{G}_{\mathrm{A}}=5 \mathrm{nS}$ and $\mathrm{G}_{\mathrm{leak}}=0.1 \mathrm{nS}$. Ci, Hyperpolarizing trace from a different cell held at $-50 \mathrm{mV}$ showing rebound spiking associated with voltage sag. $i$, Model neuron showing rebound spiking at the same holding voltage and current injection. Maximal conductances are: $\mathrm{G}_{\mathrm{Na}}=200 \mathrm{nS}, \mathrm{G}_{\mathrm{K}}=2000 \mathrm{nS}, \mathrm{G}_{\mathrm{CaL}}=1.2 \mathrm{nS}, \mathrm{G}_{\mathrm{M}}=$ $20 \mathrm{nS}, \mathrm{G}_{\mathrm{KCa}}=20 \mathrm{nS}, \mathrm{G}_{\mathrm{A}}=20 \mathrm{nS}, \mathrm{G}_{\mathrm{H}}=1 \mathrm{nS}, \mathrm{G}_{\text {leak }}=2 \mathrm{nS}$. Removal of $\mathrm{g}_{\mathrm{H}}$ (curve 1) does not inhibit rebound firing. Removal of $g_{M}$ eliminates firing (curve 2) as does removal of both currents (curve 3).

Horn and Kullmann, 2007), and prevent repetitive firing (Springer et al., 2015).

Input resistance $\left(\mathrm{R}_{\mathrm{in}}\right)$ and membrane time constant $\left(\tau_{\mathrm{m}}\right)$ were highly correlated and their values, as well as rheobase, occupy an approximately 10 -fold range. Values of $\mathrm{R}_{\text {in }}$ and $\tau_{\mathrm{m}}$ are an order of magnitude larger than values previously obtained from the same population using traditional microelectrode recordings (Blackman and Purves, 1969; Jobling and Gibbins, 1999), which indicates that the excitability of tSPNs has been substantially underestimated. Measured cell diameters in the T5 ganglion occupied a five-fold range (cf. Jobling and Gibbins, 1999). Capacitance $\left(\mathrm{C}_{\mathrm{m}}\right)$ values occupied a three-fold range, and were unrelated to cell recruitment. The strong observed relationship between $R_{\text {in }}$ and measures of firing threshold (i.e., rheobase) demonstrate that ohmic processes dominate tSPN recruitment. These observations suggest that membrane resistivity rather than cell size is the primary determinant of recruitment threshold across the population (Gustafsson and Pinter, 1984), although it is unclear whether the observed variability in excitability represents a population recruitment principle.

The preservation of the passive membrane electrical properties $R_{\text {in }}$ and $\tau_{\mathrm{m}}$ leads to synaptic events of greater amplitude and longer duration, which has important consequences for synaptic recruitment. Paravertebral neurons receive nicotinic EPSPs comprising both sub- and suprathreshold events of variable amplitude (Nishi and Koketsu, 1960; Blackman and Purves, 1969; Karila and Horn, 2000; Bratton et al., 2010). An overall increase in EPSP amplitude would convert many subthreshold events into suprathreshold events, thereby increasing tSPN firing rate (Bratton et al., 2010). Traditionally, summation of EPSPs was not thought to contribute to cell recruitment in paravertebral ganglia (North, 1986; McLachlan et al., 1997; Jänig, 2006). However, recent whole-cell recordings from rat SCG demonstrate long-duration SEPSPs with much greater capacity for summation (Springer et al., 2015). We also observed long-duration sEPSPs with decay time constant comparable to $\tau_{\mathrm{m}}$ and examples of SEPSP summation leading to cell 
recruitment. This provides direct support for the gain hypothesis for amplification of preganglionic activity (Karila and Horn, 2000; Horn and Kullmann, 2007). The observed $\tau_{\mathrm{m}}$ values indicate that tSPNs could act as integrators during states of strong preganglionic sympathetic drive from individual neurons (Jänig, 1985; Ivanov and Purves, 1989) and could widen the temporal window for coincidence detection and summation of convergent synchronous preganglionic inputs (Skok, 1973; König et al., 1996; Ratté et al., 2013). These observations support the concept that tSPNs do not merely relay preganglionic activity, but rather actively integrate and amplify sympathetic output. Metabotropic receptor-mediated changes in intrinsic membrane conductances may further amplify this process (North, 1986; Karila and Horn, 2000).

Additionally, important was the observation that all tSPNs were capable of firing repetitively, which contrasts traditional observations in all paravertebral neurons, including tSPNs, of phasic firing in response to sustained current injection (Jobling and Gibbins, 1999; Jänig, 2006; Springer et al., 2015). Recent whole-cell recordings in rat SCG similarly found paravertebral neurons were capable of repetitive firing, and suggested the discrepancy was a result of impalement conductance (Springer et al., 2015). We were able to replicate these results using our model; by introducing an impalement conductance consistent with microelectrode impalement, we were able to convert repetitively firing model neurons to phasically firing model neurons. Phasic firing after impalement injury appears to be dependent on the presence of $I_{M}$, as blocking $I_{M}$ can convert sympathetic neurons from phasic to repetitively firing (Brown and Adams, 1980; Brown and Constanti, 1980; Cassell et al., 1986; Luther and Birren, 2009). This observation was reproduced by subtracting $I_{M}$ in our model. $I_{\mathrm{KCa}}$ has also been shown to contribute to the interconversion of sympathetic neuron membrane firing properties (Sacchi et al., 1995; Luther and Birren, 2009). Thus, the firing properties of paravertebral sympathetic neurons that exhibit $I_{M}$ and $I_{\mathrm{KCa}}$ are particularly sensitive to impalement leak, which underscores the importance of using whole-cell recordings. Blackman and colleagues were able to observe repetitive firing with microelectrodes, a finding that has been consistently overlooked (Blackman and Purves, 1969). A possible explanation could be differences in ion channel expression between the mouse and guinea pig.

\section{The physiologic relevance of repetitive firing in tSPNs}

The physiologic relevance of repetitive firing in tSPNs in response to current stimulation might be dismissed if one assumes that postganglionic neurons are only driven by nicotinic preganglionic input. However, paravertebral neurons can exhibit long-lasting depolarization and sustained firing (Blackman and Purves, 1969; Jänig et al., 1982; Kawatani et al., 1987). Activation of metabotropic muscarinic and various other non-cholinergic receptors are implicated (Jänig et al., 1982; North, 1986; Kawatani et al., 1987; Elfvin et al., 1993). These studies support the idea that tSPNs can generate sustained sympathetic drive with limited influence from preganglionics.
Passive membrane properties and various conductances are responsible for sculpting the firing response of tSPNs. $R_{\text {in }}$ is important in determining firing rate over a range of injected current values. $R_{\text {in }}$ also impacts the slope of the $f$-I curve. tSPNs with steeper slope may be more effective at amplifying postganglionic output gain (Salinas and Thier, 2000; Zimmerman and Hochman, 2010). Given the relatively low steady-state firing rates of preganglionic neurons observed in vivo (Jänig, 2006), the physiologic relevance of variability in response amplification is unclear (Springer et al., 2015).

However, synaptic drive may contribute to response amplification during bouts of metabotropic receptormediated sustained activity described above. We observe spontaneous EPSCs with amplitudes ranging from $10 \mathrm{pA}$ to over $100 \mathrm{pA}$ (data not shown). Comparing these amplitudes to values of rheobase (range, 5-70 pA) supports conditions where synaptic actions are capable of transient response amplification.

\section{Relating observed cellular properties to underlying conductances}

While the firing rate of tSPNs is strongly determined by the temporal dynamics of the $A H P$, a feature carried by $I_{A}$ and $I_{K}$ in rodent SCG (Belluzzi and Sacchi, 1988), the mechanisms underlying SRA have not been studied in paravertebral ganglia including tSPNs. SRA has been well characterized elsewhere (Benda and Herz, 2003; Benda and Tabak, 2013). Contributions from $I_{M}$ and $I_{\mathrm{KCa}}$ are among the proposed mechanisms (Sawczuk et al., 1997; Powers et al., 1999; Miles et al., 2005; Yi et al., 2015), and these currents have been previously identified in rodent paravertebral ganglia (Sacchi et al., 1995; Davies et al., 1996; Haley et al., 2000; Locknar et al., 2004; Maingret et al., 2008). Our modeling found that $I_{M}$ and $I_{K C a}$ were required to replicate the fast and slow components of SRA, respectively. $I_{M}$ and $I_{\mathrm{KCa}}$ are also known to contribute to the SAHP in rodent SCG and hippocampus (Storm, 1990; Sacchi et al., 1995), and inclusion of $I_{\mathrm{KCa}}$ or $I_{M}$ in the model reproduced the sAHP after repetitive firing. That SRA ratio and SAHP half-decay were correlated further supports co-involvement of these conductances.

\section{Other factors contributing to modulation of tSPN excitability}

tSPNs are known to express $I_{A}, I_{H}$ and $I_{M}$ (Jobling and Gibbins, 1999). These currents have been shown to modulate EPSP amplitude, synaptic integration, membrane potential, and repetitive firing rate (Connor and Stevens, 1971; Storm, 1990; Rush and Rinzel, 1995; Hoffman et al., 1997; Lamas, 1998; Prescott et al., 2006; George et al., 2009; Kullmann et al., 2016). We found evidence of $I_{A}, I_{H}$ and $I_{M}$ in our recordings by observing phenomena such as notch, sag, and rebound firing, and we replicated their effects using computational modeling. These phenomena typically require hyperpolarization to emerge. While there are no known inhibitory synapses in sympathetic ganglia (McLachlan, 2007), a slow IPSP due to metabotropic activation of $\mathrm{K}^{+}$ conductances has been observed in SCG (Libet and Kobayashi, 1974; North, 1986). Another method of hyperpolarization observed in a small group of tSPNs is the slowly developing usAHP that follows prolonged activity (Zhang 
and Sillar, 2012). The usAHP has been observed in rabbit SCG (Lees and Wallis, 1974) and reflects $\mathrm{Na}^{+}$-dependent activation of the ouabain-sensitive $\alpha 3 \mathrm{Na}^{+} / \mathrm{K}^{+}$-ATPase (Picton et al., 2017). These long-lasting hyperpolarizations may provide a physiologic mechanism by which the aforementioned phenomena may emerge.

\section{References}

Ascoli GA, Gasparini S, Medinilla V, Migliore M (2010) Local control of postinhibitory rebound spiking in CA1 pyramidal neuron dendrites. J Neurosci 30:6434-6442.

Bartness TJ, Vaughan CH, Song CK (2010) Sympathetic and sensory innervation of brown adipose tissue. Int J Obes (Lond) 34 [Suppl 1]:S36-S42.

Belluzzi O, Sacchi O (1988) The interactions between potassium and sodium currents in generating action potentials in the rat sympathetic neurone. J Physiol 397:127-147.

Benda J, Herz AV (2003) A universal model for spike-frequency adaptation. Neural Comput 15:2523-2564.

Benda J, Tabak J (2013) Spike-frequency adaptation. In: Encyclopedia of computational neuroscience (Jaeger D, Jung R, eds), pp 1-12. New York: Springer New York.

Bhalla US, Bower JM (1993) Exploring parameter space in detailed single neuron models: simulations of the mitral and granule cells of the olfactory bulb. J Neurophysiol 69:1948-1965.

Blackman JG, Purves RD (1969) Intracellular recordings from ganglia of the thoracic sympathetic chain of the guinea-pig. J Physiol 203:173-198.

Bratton B, Davies P, Jänig W, McAllen R (2010) Ganglionic transmission in a vasomotor pathway studied in vivo: vasomotor ganglionic transmission in vivo. J Physiol 588:1647-1659.

Brown AG (1981) Organization in the spinal cord: the anatomy and physiology of identified neurons. London: Springer.

Brown DA (1988) M currents. In: Ion channels (Narahashi T, ed), pp 55-94. Boston, MA: Springer.

Brown DA, Constanti A (1980) Intracellular observations on the effects of muscarinic agonists on rat sympathetic neurones. $\mathrm{Br} \mathrm{J}$ Pharmacol 70:593-608.

Brown DA, Adams PR (1980) Muscarinic suppression of a novel voltage-sensitive $\mathrm{K}+$ current in a vertebrate neurone. Nature 283: 673-676.

Brownstone RM, Jordan LM, Kriellaars DJ, Noga BR, Shefchyk SJ (1992) On the regulation of repetitive firing in lumbar motoneurones during fictive locomotion in the cat. Exp Brain Res 90:441455.

Cassell JF, Clark AL, McLachlan EM (1986) Characteristics of phasic and tonic sympathetic ganglion cells of the guinea-pig. J Physiol 372:457-483

Connor JA, Stevens CF (1971) Prediction of repetitive firing behaviour from voltage clamp data on an isolated neurone soma. J Physiol 213:31-53.

Constanti A, Galvan M (1983) M-current in voltage-clamped olfactory cortex neurones. Neurosci Lett 39:65-70.

Cymbalyuk GS, Gaudry Q, Masino MA, Calabrese RL (2002) Bursting in leech heart interneurons: cell-autonomous and network-based mechanisms. J Neurosci 22:10580-10592.

Davies PJ, Ireland DR, McLachlan EM (1996) Sources of Ca2+ for different $\mathrm{Ca}(2+)$-activated $\mathrm{K}+$ conductances in neurones of the rat superior cervical ganglion. J Physiol 495:353-366.

Eccles JC (1935) The action potential of the superior cervical ganglion. J Physiol 85:179-206.

Elfvin L-G, Lindh B, Hökfelt T (1993) The chemical neuroanatomy of sympathetic ganglia. Annu Rev Neurosci 16:471-507.

Engbers JD, Anderson D, Tadayonnejad R, Mehaffey WH, Molineux ML, Turner RW (2011) Distinct roles for $I(T)$ and $I(H)$ in controlling the frequency and timing of rebound spike responses. J Physiol 589:5391-5413.
Ermentrout GB, Terman DH (2010) Mathematical foundations of neuroscience. Berlin: Springer.

Erulkar SD, Woodward JK (1968) Intracellular recording from mammalian superior cervical ganglion in situ. J Physiol 199:189-203.

Ferrante M, Shay CF, Tsuno Y, William Chapman G, Hasselmo ME (2017) Post-inhibitory rebound spikes in rat medial entorhinal layer II/III principal cells: in vivo, in vitro, and computational modeling characterization. Cereb Cortex 27:2111-2125.

Furlan A, La Manno G, Lübke M, Häring M, Abdo H, Hochgerner $\mathrm{H}$ Kupari J, Usoskin D, Airaksinen MS, Oliver G, Linnarsson S, Ernfors $P$ (2016) Visceral motor neuron diversity delineates a cellular basis for nipple- and pilo-erection muscle control. Nat Neurosci 19:1331-1340.

Galvan M, Sedlmeir C (1984) Outward currents in voltage-clamped rat sympathetic neurones. J Physiol 356:115-133.

George MS, Abbott LF, Siegelbaum SA (2009) HCN hyperpolarization-activated cation channels inhibit EPSPs by interactions with M-type $\mathrm{K}(+)$ channels. Nat Neurosci 12:577-584.

Gibbins IL (1991) Vasomotor, pilomotor and secretomotor neurons distinguished by size and neuropeptide content in superior cervical ganglia of mice. J Auton Nerv Syst 34:171-183.

Golowasch J, Thomas G, Taylor AL, Patel A, Pineda A, Khalil C, Nadim F (2009) Membrane capacitance measurements revisited: dependence of capacitance value on measurement method in nonisopotential neurons. J Neurophysiol 102:2161-2175.

Gustafsson B, Pinter MJ (1984) An investigation of threshold properties among cat spinal alpha-motoneurones. J Physiol 357:453.

Haley JE, Delmas P, Offermanns S, Abogadie FC, Simon MI, Buckley NJ, Brown DA (2000) Muscarinic inhibition of calcium current and M current in Galpha q-deficient mice. J Neurosci 20:3973-3979.

Hines ML, Morse T, Migliore M, Carnevale NT, Shepherd GM (2004) ModelDB: a database to support computational neuroscience. J Comput Neurosci 17:7-11.

Hochman S, McCrea DA (1994) Effects of chronic spinalization on ankle extensor motoneurons. II. Motoneuron electrical properties. J Neurophysiol 71:1468-1479.

Hoffman DA, Magee JC, Colbert CM, Johnston D (1997) K+ channel regulation of signal propagation in dendrites of hippocampal pyramidal neurons. Nature 387:869-875.

Horn JP, Kullmann PHM (2007) Dynamic clamp analysis of synaptic integration in sympathetic ganglia. Neurophysiology 39:423-429.

Ivanov A, Purves D (1989) Ongoing electrical activity of superior cervical ganglion cells in mammals of different size. J Comp Neurol 284:398-404

Jänig W (1985) Organization of the lumbar sympathetic outflow to skeletal muscle and skin of the cat hindlimb and tail. Rev Physiol Biochem Pharmacol 102:119-213.

Jänig W, Krauspe R, Wiedersatz G (1982) Transmission of impulses from pre- to postganglionic vasoconstrictor and sudomotor neurons. J Auton Nerv Syst 6:95-106.

Jänig W (2006) The integrative action of the autonomic nervous system. New York: Cambridge University Press.

Jobling P, Gibbins IL (1999) Electrophysiological and morphological diversity of mouse sympathetic neurons. J Neurophysiol 82:27472764.

Karila P, Horn JP (2000) Secondary nicotinic synapses on sympathetic $B$ neurons and their putative role in ganglionic amplification of activity. The J Neurosci 20:908-918.

Kawatani M, Rutigliano MJ, de Groat WC (1987) Vasoactive intestinal polypeptide facilitates the late component of the 5-hydroxytryptamine-induced discharge in the cat superior cervical ganglion. Neurosci Lett 73:59-64.

König P, Engel AK, Singer W (1996) Integrator or coincidence detector? The role of the cortical neuron revisited. Trends Neurosci 19:130-137.

Kullmann PH, Sikora KM, Clark KL, Arduini I, Springer MG, Horn JP (2016) HCN hyperpolarization-activated cation channels strengthen virtual nicotinic EPSPs and thereby elevate synaptic amplification in rat sympathetic neurons. J Neurophysiol 116:438447. 
Kurian M, Crook SM, Jung R (2011) Motoneuron model of selfsustained firing after spinal cord injury. J Comput Neurosci 31: 625-645.

Lamas JA (1998) A hyperpolarization-activated cation current (Ih) contributes to resting membrane potential in rat superior cervical sympathetic neurones. Pflugers Arch 436:429-435.

Lees GM, Wallis DI (1974) Hyperpolarization of rabbit superior cervical ganglion cells due to activity of an electrogenic sodium pump. $\mathrm{Br} \mathrm{J}$ Pharmacol 50:79-93.

Li C, Horn JP (2006) Physiological classification of sympathetic neurons in the rat superior cervical ganglion. J Neurophysiol 95: 187-195.

Libet B, Kobayashi H (1974) Adrenergic mediation of slow inhibitory postsynaptic potential in sympathetic ganglia of the frog. J Neurophysiol 37:805-814.

Lichtman JW, Purves D, Yip JW (1980) Innervation of sympathetic neurones in the guinea-pig thoracic chain. J Physiol 298:285-299.

Locknar SA, Barstow KL, Tompkins JD, Merriam LA, Parsons RL (2004) Calcium-induced calcium release regulates action potential generation in guinea-pig sympathetic neurones. J Physiol 555: 627-635.

Lu C, Fuchs E (2014) Sweat gland progenitors in development, homeostasis, and wound repair. Cold Spring Harb Perspect Med 4.

Luther JA, Birren SJ (2009) p75 and TrkA signaling regulates sympathetic neuronal firing patterns via differential modulation of voltage-gated currents. J Neurosci 29:5411-5424.

Maingret F, Coste B, Hao J, Giamarchi A, Allen D, Crest M, Litchfield DW, Adelman JP, Delmas P (2008) Neurotransmitter modulation of small-conductance $\mathrm{Ca} 2+$-activated $\mathrm{K}+$ channels by regulation of Ca2+ gating. Neuron 59:439-449.

Masliukov PM, Timmermans JP (2004) Immunocytochemical properties of stellate ganglion neurons during early postnatal development. Histochem Cell Biol 122:201-209.

McLachlan EM (2003) Transmission of signals through sympathetic ganglia-modulation, integration or simply distribution? Acta Physiol Scand 177:227-235.

McLachlan EM (2007) Diversity of sympathetic vasoconstrictor pathways and their plasticity after spinal cord injury. Clin Auton Res 17:6-12.

McLachlan EM, Davies PJ, Häbler HJ, Jamieson J (1997) On-going and reflex synaptic events in rat superior cervical ganglion cells. J Physiol 501:165-181.

McLachlan EM, Häbler HJ, Jamieson J, Davies PJ (1998) Analysis of the periodicity of synaptic events in neurones in the superior cervical ganglion of anaesthetized rats. J Physiol 511:461-478.

Miles GB, Dai Y, Brownstone RM (2005) Mechanisms underlying the early phase of spike frequency adaptation in mouse spinal motoneurones. J Physiol 566:519-532.

Nishi S, Koketsu K (1960) Electrical properties and activities of single sympathetic neurons in frogs. J Cell Comp Physiol 55:15-30.

North RA (1986) Mechanisms of autonomic integration. In: The nervous system, intrinsic regulatory systems of the brain, pp 115-153. New York: Oxford University Press.

Pape HC (1996) Queer current and pacemaker: the hyperpolarizationactivated cation current in neurons. Annu Rev Physiol 58:299-327.

Picton LD, Nascimento F, Broadhead MJ, Sillar KT, Miles GB (2017) Sodium pumps mediate activity-dependent changes in mammalian motor networks. J Neurosci 37:906-921.

Platkiewicz J, Brette R (2010) A threshold equation for action potential initiation. PLoS Comput Biol 6:e1000850.

Powers RK, Sawczuk A, Musick JR, Binder MD (1999) Multiple mechanisms of spike-frequency adaptation in motoneurones. $J$ Physiol 93:101-114.

Prescott SA, Ratté S, De Koninck Y, Sejnowski TJ (2006) Nonlinear interaction between shunting and adaptation controls a switch between integration and coincidence detection in pyramidal neurons. J Neurosci 26:9084-9097.
Prinz AA, Bucher D, Marder E (2004) Similar network activity from disparate circuit parameters. Nat Neurosci 7:1345-1352.

Purves D, Wigston DJ (1983) Neural units in the superior cervical ganglion of the guinea-pig. J Physiol 334:169-178.

Rall W (2011) Core conductor theory and cable properties of neurons. In: Handbook of physiology, the nervous system, cellular biology of neurons, pp 39-97. Bethesda: American Physiological Society.

Ratté S, Hong S, De Schutter E, Prescott SA (2013) Impact of neuronal properties on network coding: roles of spike initiation dynamics and robust synchrony transfer. Neuron 78:758-772.

Rimmer K, Horn JP (2010) Weak and straddling secondary nicotinic synapses can drive firing in rat sympathetic neurons and thereby contribute to ganglionic amplification. Front Neurol 1:130.

Rittenhouse AR, Zigmond RE (1999) Role of N- and L-type calcium channels in depolarization-induced activation of tyrosine hydroxylase and release of norepinephrine by sympathetic cell bodies and nerve terminals. J Neurobiol 40:137-148.

Rush ME, Rinzel J (1995) The potassium A-current, low firing rates and rebound excitation in Hodgkin-Huxley models. Bull Math Biol 57:899-929.

Sacchi O, Rossi ML, Canella R (1995) The slow Ca(2+)-activated K+ current, IAHP, in the rat sympathetic neurone. J Physiol 483:15-27.

Salinas E, Thier P (2000) Gain modulation: a major computational principle of the central nervous system. Neuron 27:15-21.

Sawczuk A, Powers RK, Binder MD (1997) Contribution of outward currents to spike-frequency adaptation in hypoglossal motoneurons of the rat. J Neurophysiol 78:2246-2253.

Schäfer MK, Eiden LE, Weihe E (1998) Cholinergic neurons and terminal fields revealed by immunohistochemistry for the vesicular acetylcholine transporter. II. The peripheral nervous system. Neuroscience 84:361-376.

Schütz B, Schäfer MK, Gördes M, Eiden LE, Weihe E (2015) Satb2independent acquisition of the cholinergic sudomotor phenotype in rodents. Cell Mol Neurobiol 35:205-216.

Skok VI (1973) Physiology of autonomic ganglia. Tokyo: Igaku Shoin. Springer MG, Kullmann PHM, Horn JP (2015) Virtual leak channels modulate firing dynamics and synaptic integration in rat sympathetic neurons: implications for ganglionic transmission in vivo. J Physiol 593:803-823.

Staley KJ, Otis TS, Mody I (1992) Membrane properties of dentate gyrus granule cells: comparison of sharp microelectrode and whole-cell recordings. J Neurophysiol 67:1346-1358.

Stauffer EK, McDonagh JC, Hornby TG, Reinking RM, Stuart DG (2007) Historical reflections on the afterhyperpolarization-firing rate relation of vertebrate spinal neurons. J Comp Physiol A 193: 145-158.

Storm JF (1990) Potassium currents in hippocampal pyramidal cells. Prog Brain Res 83:161-187.

Valli P, Zucca G, Botta L, Seghezzi R (1989) Lumbar sympathetic ganglia in man: an electrophysiological study in vitro. J Auton Nerv Syst 28:211-217.

Venance L, Glowinski J (2003) Heterogeneity of spike frequency adaptation among medium spiny neurones from the rat striatum. Neuroscience 122:77-92.

Wheeler DW, Kullmann PH, Horn JP (2004) Estimating usedependent synaptic gain in autonomic ganglia by computational simulation and dynamic-clamp analysis. J Neurophysiol 92:2659-2671.

Yi G, Wang J, Tsang KM, Wei X, Deng B, Han C (2015) Spikefrequency adaptation of a two-compartment neuron modulated by extracellular electric fields. Biol Cybern 109:287-306.

Zhang HY, Sillar KT (2012) Short-term memory of motor network performance via activity-dependent potentiation of $\mathrm{Na}+/ \mathrm{K}+$ pump function. Curr Biol 22:526-531.

Zimmerman A, Hochman S (2010) Heterogeneity of membrane properties in sympathetic preganglionic neurons of neonatal mice: evidence of four subpopulations in the intermediolateral nucleus. $J$ Neurophysiol 103:490-498. 